\title{
Indian Farmers' Valuation of Yield Distributions: Will poor farmers value 'pro-poor' seeds?
}

\begin{abstract}
Potential poverty traps among the rural poor suggest a need to reduce poor farmers' vulnerability by stabilizing crop yields and limiting yield losses. Advances in biotechnology will help address this need directly with crops that tolerate climate fluctuation or resist biotic stresses. Evaluating ex ante how farmers will value these 'propoor' seeds is important for delivery design, but also challenging. This paper describes an experimental economic approach to understanding farmers' valuation of such seeds. Using data from a survey and experiment, I assess Indian farmers' valuation of changes in the mean, variance, and skewness of payoff distributions. These farmers value increases in expected value, but seem indifferent about higher moment changes in payoff distributions. Farmer traits such as wealth and risk exposure affect their valuation of these changes only mildly. While various limitations to the experimental approach must qualify practical implications of these findings, the experiment demonstrates the viability of conducting valuation experiments with open-ended questions in developing countries.
\end{abstract}

JEL: C9-Design of Experiments, D8-Uncertainty, O1-Economic Development, Q1-Agriculture Keywords: Poverty, Risk, Biotechnology, Experimental Economics

\section{INTRODUCTION}

Uncertainty is a defining feature of poverty (Banerjee 2004). The poor, especially in poor countries, lack access to resources and institutions that can reduce routine fluctuations in consumption, income or wealth and moderate catastrophic asset or health shocks (see Dercon 2004, Wood 2003, World Bank 2000). Studies that find empirical evidence for poverty traps among the rural poor (e.g., Barrett, et al. 2001, Carter and May 1999, Dercon 1998, Lybbert, et al. 2004, Zimmerman and Carter 2003) suggest a need to reduce poor farmers' vulnerability by stabilizing crop yields and limiting yield losses.

Crop yields are risky because they depend on weather (especially temperature and the amount and timing of precipitation), biotic stresses (pests and diseases), and the optimal timing of inputs (fertilizers, pesticides and weeding), all of which are stochastic (Roumasset 1976). Advances 
in agricultural biotechnology have enabled breeders to reduce farmers' exposure to all three of these sources of risk more directly than ever before. Soon, crops that tolerate drought and extreme temperatures or resist disease, viruses, bacteria or insects will be available to many farmers. The welfare gains for poor farmers who are particularly vulnerable to routine climate fluctuations and catastrophic crop losses could be substantial. Of course, realizing these welfare gains requires that vulnerable farmers adopt these new seeds. Will the poor farmers who could benefit most choose to purchase such risk-reducing seeds?

Generally, even poor farmers will pay a significant premium for seeds with higher expected yield (David and Sperling 1999), but valuing seeds that reduce risk may be particularly challenging. The relative benefit of such a seed is a function of the targeted stochastic variable (e.g., weather, pests, etc.) and is hence also stochastic. Thus, the advantage of these seeds will not be apparent every season, which may slow learning. Many such seeds will be developed and delivered by the private sector and may carry a price premium, which has implications for the riskiness of a seed's net returns (Binswanger 1979). For example, farmers paying a premium for pest resistant seeds could lose money during low pest load seasons, leading to potentially erratic patterns of adoption and disadoption. Such a learning process can be especially painful for poor farmers who are unable to survive "a bad year or two in an optimal policy sequence" (Lipton 1968, p. 335). In short, farmers' valuation of seeds that reduce risk will hinge on their risk preferences and on inter-seasonal learning in ways quite different from their valuation of other sorts of seeds - ways that make ex ante assessment of their valuation challenging as well.

The objective of this paper is to infer Indian farmers' valuation of risk-reducing seeds using experimental payoff distributions and to explore a field experiment research methodology for informing these challenging valuation questions. The experimental approach used elicits farmers risk preferences, allows for learning across repeated rounds of the experiment, and directly assesses farmers' valuation of changes in the mean, variance and skewness of a payoff distribution. I 
conclude that these farmers value increases in expected value arising from unconditional upward shifts in the payoff distribution but seem indifferent about higher moment changes. Farmer traits such as wealth and risk exposure affect farmers' valuation of changes in these distributions only mildly. While these results relate to farmers' valuation of risk-reducing 'pro-poor' seeds, limitations of the experimental methodology must qualify any practical implications.

After providing a background to pro-poor seeds and farmers' seed preferences in the next section, I present a simple model in section 3 that analytically captures possible pro-poor of riskreducing seeds. Later empirical analysis tests the logic of this simple model. In section 4, I describe the survey and the experiment conducted with Indian farmers in Tamil Nadu state and present some descriptive statistics. Section 5 contains the econometric analysis of data from the survey and experiment. Sections 6 and 7, respectively, discuss various limitations of the experimental methodology in this case and present conclusions.

\section{BACKGROUND}

Presently, seeds that are considered pro-poor confer three types of benefits: (a) higher expected yield to address problems such as macro-nutrient deficiency, lack of market entitlements, and chronic abiotic stresses such as soil salinity and low soil fertility, (b) higher micro-nutrient content to address micro-nutrient deficiency problems, and (c) lower yield risk via better yield stability or lower downside yield fluctuation to address problems such as food security and income stability. Poor farmers' valuation of these benefits will affect the uptake of pro-poor seeds, but may be difficult to assess in the case of micronutrient or yield risk benefits. This paper discusses an experimental approach to assessing farmers' valuation of the latter. As background, this section highlights the logic behind the presumed pro-poor benefits of reducing yield risk, discusses recent examples of risk-reducing seeds, and provides an overview of seed preferences and demand among poor farmers. 
The section closes with a brief overview of the growing body of research in development economics that uses experimental methodologies.

Risk-reducing seeds benefit the poor by reducing vulnerability. Lipton and Longhurst (1989) comment on this as they dissect the impact of modern varieties on the poor. Their contrast of the goals of plant science and those of poor farmers highlights why higher moments of yield distributions should matter to the poor:

Breeders see quantity (as indicated by yield) - and, some way behind, quality - as overwhelmingly their main goals... A poor farmer would still wonder about three missing items. They are stability, sustainability, and cross-crop effects. [M]ost breeders may well see them as long-term components of yield. Indeed, a lower risk of downward fluctuation in crop output, or of its long-run decline, is ultimately a form of increased yield. However, poor farmers also value stability as such independently of yield, and even at its expense. They cannot afford to take big risks. (Lipton and Longhurst 1989, pp 28-29)

Yield stability may be particularly important to poor farmers in rainfed areas where variable rainfall and inherently unstable food production drive poverty dynamics (DeVries and Toenniessen 2001). These sensible observations frame yield risk benefits as being distinctly pro-poor. Before assessing farmers' valuation of these benefits, however, it is helpful to capture this logic more formally, which will be taken up with the simple model in the next section.

Recent advances in science have enabled breeders to improve yield stability through resistance to biotic or climatic stresses. Since the mid-1980s, yield stability has been an increasingly important component of traditional plant breeding (Traxler, et al. 1995). Thanks to biotechnological advances, it is now possible to address several stability and micro-nutrient problems, including those that were previously intractable (Conway 1997, DeVries and Toenniessen 2001). Resulting genebased technologies may also facilitate seed adoption and use, making these benefits more accessible to poor farmers. Specific recent examples include mosaic-resistant cassava in Uganda, Mendel Biotechnology's 'drought protection' technology, disease-resistant banana, virus- and pest-resistant sugar cane, and virus-resistant sweet potato (Wambugu 1999). A more widely familiar example involves $B t$ cotton, which through the $B t$ gene provides resistance to boring pests and protects 
farmers from catastrophic crop losses in high pest load years. Although there remains some debate, Bt cotton benefits also appear to be distinctly pro-poor (Ismael, et al. 2002, Thirtle, et al. 2003). ${ }^{1}$

Farmers' seed preferences will ultimately shape adoption patterns of these emerging, riskreducing seeds. These preferences are determined largely by farmer traits. Differences in resource endowment, management strategy and market situation affect farmers' valuation of seed production traits (yield potential and stability), consumption traits (taste, color, texture), economic traits (early maturity, market demand, storability), and cultural traits (beliefs, rituals) (Cromwell, et al. 1992, Louwaars, et al. 1997). In many developing countries, farmers range from large-scale commercial to small-scale semi-commercial to subsistence (Cromwell, et al. 1992), which translates into complex seed preferences in the aggregate. This degree of heterogeneity across farmer types often makes the spread of even seemingly-superior seed varieties difficult to predict (David and Sperling 1999).

More than ever, the seed preferences of poor farmers are manifest in market demand as they increasingly procure seeds from the private sector for both cash and subsistence crops (David and Sperling 1999, Pray and Fuglie 2000, Tripp and Pal 2000). Seed demand generally tends to be price inelastic. Indeed, several other variables affect farmers seed purchase decisions more than price. Physical access to an appropriate quantity of quality seeds, the timing of availability, and information about seed are often more important than the seed price (Cromwell, et al. 1992, Heisey and Brennan 1991, Rohrbach and Malusalila 2000, Tripp 2001). The yield advantage, seed rate, and production and market risk of a seed also directly influence farmers' decision to adopt a new seed (Feder, et al. 1985). ${ }^{2}$ While all this may be true in general, price remains a critical issue for poor farmers. These

\footnotetext{
${ }^{1}$ Although some worry that poor farmers who become dependent on the Bt gene for protection against pests will be particularly hurt if (when) pests develop resistance to Bt (Lipton 2001).

${ }^{2}$ Generally, other determinants of technology adoption are equally relevant. Farm characteristics such as size, topography and soil quality are important adoption determinants, as are farmer characteristics such as gender (Cameron 1999) and education (Pitt and Sumodiningrat 1991), and household wealth and size. Farmers' perceptions about the complexity and relative risk of a technology likewise affect adoption (Adesina and Baidu-Forson 1995, Batz, et al. 1999). Information about the value of a new technology is paramount, so learning-by-doing (Cameron 1999), learning from others (Foster and Rosenzweig 1995), and - to a lesser extent - formal extension are critical adoption determinants. Market imperfections often imply differences in transactions costs (Holloway, et al. 2000), access to
} 
vulnerable farmers tend to be more sensitive to seed price than other farmers because they devote a larger portion of their less input-intensive production costs to seed purchases. Thus saving seed - a viable option for many poor farmers given their opportunity costs and management strategies often provides a cheaper, if inferior, substitute to seeds purchased from dealers (Louwaars, et al. 1997).

Since the aim of this paper is partly methodological, this section ends with a brief background to experimental techniques as applied to development economics. In the last decade, many experimental economists have ventured into the field in pursuit of richer decision-making contexts and more varied subject pools. These field experiments in economics are methodologically distinct from and complementary to laboratory experiments in several important ways (see Carpenter, et al. 2005). Although still nascent, field experiments have been used in development economics to measure cooperation, trust, altruism, fairness, and risk and time preferences (see Cardenas and Carpenter 2004 for a comprehensive review). Experimental efforts to asses risk preferences among poor farmers began with Binswanger (1980), who offered Indian farmers dichotomous choices among pairs of gambles and concluded that these farmers were moderately risk averse regardless of wealth or other farmer traits, suggesting that farmers' constraint sets (e.g., access to credit and inputs) explain behavioral differences between farmers of differing wealth better than risk preferences. Others have investigated risk preferences using dichotomous choice experiments more recently with experiments designed to test expected utility theory (Humphrey and Verschoor 2004a, Humphrey and Verschoor 2004b). The research in this paper builds on these efforts to assess risk preferences with an experiment that uses open-ended questions, which more accurately elicit risk preferences and can address a wider range of research questions.

credit (Feder, et al. 1985) and capacity to mitigate and manage risk (Batz, et al. 1999), which can all significantly affect the pattern of adoption among different farmers. 


\section{MODEL}

How should farmers value changes in yield distributions? How should a farmer's wealth affect his valuation of these changes? This section presents a stylized, two-season model that analytically captures the logic behind the pro-poor benefits of risk-reducing seeds. Econometric analysis in a subsequent section tests this logic.

Suppose that in the current season farmers receive a net income stream from existing assets $\left(w_{i}\right)$ and have the option of planting an additional seed variety. To isolate valuation of the yield distribution from any scale effects, assume all farmers face the same discrete planting decision: whether or not to plant the new seed on a single acre. Assume further that farmers' wealth in the second season is fully determined by first season net income $\left(\pi_{i 1}\right)$ according to a commonly known recursion function $f\left(\pi_{i 1}\right)$. Finally, assume that markets for inputs, output and consumption goods are complete and that farmers are price-takers in these markets (i.e., separability) so that maximizing the utility of total net income and maximizing the utility of consumption generate the same optimal production decisions. The decision whether or not to plant the seed thus involves the problem:

$$
\max _{d_{i}=\{0,1\}} V\left(\pi_{i 1}\right)=u\left(\pi_{i 1}\right)+\delta u\left(f\left(\pi_{i 1}\right)\right)
$$

where

$$
\pi_{i 1}=\left(1-d_{i}\right) w_{i}+d_{i}\left(y(\mathbf{z}, \varepsilon)-p+w_{i}\right)
$$

and $V($.$) is the intertemporal utility function, u($.$) is a concave and monitonically increasing utility$ function, $\delta<1$ is the discount factor, $d_{i}=1$ if farmer $i$ plants the seed with $d_{i}=0$ otherwise, $y(\mathbf{z}, \varepsilon)$ is the net yield function for the seed measured in per acre monetary units, $\mathbf{z}$ is a vector of inputs, $\varepsilon$ is stochastic yield risk with a probability density function $h(\varepsilon)$, and $p$ is the purchase price of the new seed. Net yield $y($.$) is net of all inputs except the seed in order to focus on the seed price, p$. To isolate the seed purchase decision further, $w_{i}$ captures all other income or transfers net of any associated costs. Farmers differ only in $w_{i}$ to emphasize how wealth affects valuation. 
Assume that the new seed has constant returns to scale and that farmers exhibit no systematic technical or allocative inefficiencies. This implies that the optimal input vector per acre $\left(\mathbf{z}^{*}\right)$ is the same for all farmers, as is the optimal stochastic net yield function $y=y\left(\varepsilon \mid \mathbf{z}^{*}\right)=y(\varepsilon)$. With this assumption the problem becomes

$$
\max _{d_{i}=\{0,1\}}\left(1-d_{i}\right) V\left(w_{i}, f\left(w_{i}\right)\right)+d_{i} E\left[V\left(y(\varepsilon)-p+w_{i}, f\left(y(\varepsilon)-p+w_{i}\right)\right)\right]
$$

where $E$ is the expectation operator. This discrete planting decision implies a maximum willingnessto-pay $\left(p^{*}\right)$ defined as

$$
V\left(w_{i}, f\left(w_{i}\right)\right)=E\left[V\left(y(\varepsilon)-p^{*}+w_{i}, f\left(y(\varepsilon)-p^{*}+w_{i}\right)\right)\right]
$$

and the decision rule: purchase and plant if and only if $p \leq p^{*}$.

As mentioned in the prior section, yield stability and lower downside yield risk are presumably pro-poor because many poor farmers subsist precariously close to critical survival thresholds. To capture this important rationale for pro-poor seeds that reduce risk, suppose that the wealth recursion function $f($.$) takes the simple form$

$$
\pi_{i 2}=f\left(\pi_{i 1}\right)=\left\{\begin{array}{l}
\pi_{i 1} \text { if } \pi_{i 1}>\pi^{0} \\
0 \quad \text { if } \pi_{i 1} \leq \pi^{0}
\end{array}\right.
$$

Provided that farmers perceive these bifurcated wealth dynamics, the intertemporal utility function $V($.$) is directly shaped by f($.$) as follows:$

$$
V\left(\pi_{i 1}\right)=\left\{\begin{array}{cc}
\pi_{i 1}(1+\delta) & \text { if } \pi_{i 1}>\pi^{0} \\
\pi_{i 1} & \text { if } \pi_{i 1} \leq \pi^{0}
\end{array}\right.
$$

The discontinuity in this intertemporal utility function implies that farmer $i$ values that portion of the net yield distribution below $y_{i}^{0}=\pi^{0}+p-w_{i}$ differently than that above $y_{i}^{0}$ since any yield $y>y_{i}^{0}$ pushes him safely above the trap threshold $\pi^{0}$. 
The effect of this discontinuity is easy to portray graphically by superimposing the yield risk pdf $h(\varepsilon)$ on the function $V\left(\pi_{i 1}\right)$ as shown in Figure $1 .{ }^{3}$ While farmers all face the same yield risk by assumption and the shape of the $h(\varepsilon)$ pdf is therefore the same for all farmers, the location of this distribution is farmer-specific: $h(\varepsilon)$ is positioned relative to $\pi^{0}$ according to $w_{i}$. In Figure $1, h\left(\varepsilon \mid w_{i}\right)$ therefore captures both the shape and the horizontal location of the net yield distribution for farmer i. A farmer's valuation of the distribution $h\left(\varepsilon \mid w_{i}\right)$ hinges crucially on the tail of $h\left(\varepsilon \mid w_{i}\right)$ below $\pi^{0}$, denoted as probability $\theta_{i}$ where

$$
\theta_{i}=\operatorname{Pr}\left(y+w_{i} \leq \pi^{0}\right)=\operatorname{Pr}\left(y \leq y_{i}^{0}\right)=\int_{-\infty}^{y_{i}^{0}} h\left(\varepsilon \mid w_{i}\right) d \varepsilon
$$

Figure 1 clearly shows that farmers' valuation of a yield distribution should be inversely related to $\theta_{i}$. Any improvement in yield stability or resistance to catastrophic loss in this model reduces $\theta_{i}$ and helps to push farmers above the trap threshold. While the concavity assumption on $u($.$) (i.e., risk$ aversion) implies that all farmers value a reduction in $\theta_{i}$, the presence of a known trap can substantially increase the value of seeds with stabilized or truncated yield distributions - especially for poor farmers who subsist near the trap threshold.

This simple model provides an abstract depiction of the logic behind the pro-poor benefits of seeds that reduce downside risk. As captured in the model, farmers benefit from any reduction in the lower tail of a yield distribution, but such a reduction disproportionately benefits poor farmers for whom a bad harvest can have catastrophic long-run consequences. For many, a series of bad harvest draws can quickly make even the kind of draconian subsistence threshold captured in this model a relevant threat. All such farmers should warmly welcome 'pro-poor' seeds that reduce downside risk through stabilized or truncated distributions. I use the data described in the next section to test this logic among Indian farmers.

\footnotetext{
${ }^{3}$ Analytical results of the model are available on request. An analytical approach to the model yields the same results, albeit less concisely than the graphical approach taken in this paper.
} 


\section{DATA}

To infer farmers' valuation of stabilized and truncated crop yield distributions, this paper uses data from the Salem and Perambalur districts of Tamil Nadu state, India. This state was selected because Tamil Nadu Agricultural University provided administrative and logistical support as a collaborating institution in the Agricultural Biotechnology Support Program II, which funded this research. Salem and Perambalur districts were selected because these districts constitute Tamil Nadu's 'cotton belt.' Some cotton farmers in this area had adopted Bt cotton by 2003 - mostly the MECH 162 and 184 varieties of Monsanto-MAHYCO's Bollguard ${ }^{\mathrm{TM}}$ cotton - which reduces risk of losses to boring pests. Including these farmers in the survey and experiment allows for comparisons between their revealed valuation of the $B t$ gene and their experimental valuation of related changes in payoff distributions. $^{4}$

Ten enumerators on the research team surveyed 290 households in three Perambalur villages (Annukur, Pandagapadi, and Namaiyur) and three Salem villages (Vellaiyur, Kilakku Raajapalayam, and Kavarparnai). These villages were selected from the 12 or so villages in Tamil Nadu that presently have more than $18 \mathrm{Bt}$ cotton farmers. A map of study area is shown in Figure 2 . With the villages selected, the research team used choice-based stratified sampling to ensure the participation of $B t$ cotton farmers and other farmers. The team constructed a list of all the $B t$ cotton famers in a village and randomly selected Bt cotton farmers, then randomly selected other farmers with the assistance of the village administrative officer.

The research team collected data from selected farmers in two parts. In the first part, enumerators administered a detailed household questionnaire focused on farmers' management

\footnotetext{
${ }^{4}$ In many settings the Bt gene primarily protects against catastrophic loss during heavy pest load seasons thereby truncating the lower tail of the yield distribution, but in India the Bt gene seems to protect cotton from catastrophic and chronic pest losses and thus may truncate as well as shift the cotton yield distribution (Qaim and Zilberman 2003). Since it is impossible to disentangle farmers valuation of a distribution shift from a truncation in this case, assessing
} 
decisions, valuation of seed traits, risk exposure and wealth. In the second part, the team conducted experiments with farmers to elicit their valuation of hypothetical yield distributions. Farmers earned money (Rupees, Rs) according to their performance in the experiment. The first subsection below describes the experiment in detail. The second subsection presents descriptive statistics.

Experimental Design: The experiment used for this paper was designed as far as possible according to standard experimental economic principles (see Davis and Holt 1993, ch.8). Initial designs were refined through field pre-testing with farmers to simplify the structure and presentation of the experiment. The primary departure from standard experimental economics involved the degree of abstractness. By necessity, the experiment was based clearly in a farming context. This context improved farmer comprehension and adds relevance to inferences to crop yield distributions. While abandoning some abstractness in favor of context seems defensible in this case, a core challenge in designing the experiment was striking an appropriate balance between abstractness and context. This challenge is addressed in greater detail in the discussion section below.

The experiment consisted of a series of hypothetical farming seasons. At the beginning of each season, farmers were offered a 'seed' with a known Rupee-payoff distribution. This distribution was explained simply and repeatedly and shown graphically in order to facilitate farmers' understanding of the payoff distribution implied by a given 'seed.' The distribution of a particular 'seed' was represented by 10 chips in a small black bag. There were three colors of chips, each representing a 'harvest' payoff: blue (high), white (average), and red (low). The distribution was modified by changing the proportion of blue, white and red chips in the bag. The contents of the bag - the number of chips of each color - were displayed on a large board at the front of the room.

farmers' valuation of $B t$ cotton does not further the objective of this paper. Instead, farmers $B t$ cotton adoption choices are taken as a general indication of a farmer's approach to seed valuation and farm management. 
The precise format of this display was modified in pre-testing to ensure that farmers understood the distribution they were valuing.

Farmers' valuation of the seed was elicited using an open-ended question, which generally elicits true values better than dichotomous choice questions (Balistreri, et al. 2001, Coursey, et al. 1999). A well established technique in experimental economics, the Becker-DeGroot-Marschak (BDM) mechanism (Becker, et al. 1964), was used to encourage farmers to report their true valuation. Following the BDM mechanism, each farmer expressed his maximum WTP for the offered seed before the price of the seed was known. The seed price was then randomly drawn from a uniform distribution of prices. Only farmers who were willing to pay at least this random seed price 'purchased and planted' the seed. To make the BDM mechanism more tangible for farmers, the lead enumerator would explain that the mechanism worked much like sending money with a trusted friend to purchase the seed on their behalf without first knowing the seed price. If the friend had enough money with him to cover the seed price once he observed the price, he would purchase the seed and return any surplus money. If he did not have enough money to cover the seed price, he would not purchase the seed and return the money in full. This imagery effectively helped farmers to realize that it was always in their best interest to send exactly what the seed was worth to them, which is precisely the advantage of the BDM mechanism (Becker, et al. 1964).

Once the farmers knew whether they had 'purchased and planted' the seed and how much they paid for it, the lead enumerator would ask a farmer to draw a chip from the bag to determine that season's harvest payoff in 'game Rupees' (explained below). Farmers' net seed earnings for the season were computed as the harvest payoff minus the seed price. At the end of each season, all farmers - those who 'purchased and planted' the seed and those who did not - received 50 game Rupees in 'off-farm earnings'.

Each seed and its corresponding yield distribution was offered for five consecutive seasons: four practice seasons, then one 'high-stakes' season. As is common in experimental economics, the 
difference between a practice season and a 'high-stakes' season was the rate at which game Rupees were exchanged for real Rupees. All game Rupees earned in practice seasons were exchanged for real Rupees at a rate of 1/100 (real Rs./game Rs.). Game Rupees earned in high-stakes seasons were exchanged for real Rupees at a rate of $1 / 10$. This format is popular in many experimental designs because it allows for learning, but provides incentives throughout the learning process, and because participants see the same payoff numbers (i.e., game Rupees) in practice rounds as they do in highstakes rounds, which reduces confusion and allows the researcher to identify the effect of higherstakes since this is the only parameter that changes in a high-stakes round (see Irwin, et al. 1998 for another example of the use of practice rounds).

While the design of the experiment aimed to elicit farmers' valuation as accurately as possible, there were two systematic 'game effects' that influenced the high-stakes WTP of many farmers. First, many farmers who did not purchase the seed in one season would increase their WTP in the next season to increase their chances of playing the game. ${ }^{5}$ Second, many farmers who played the game and had a positive (negative) harvest payoff in one season often increased (cautiously lowered) their bids in the following season. In the econometric analysis of the next section, I control for these two game effects.

There were five payoff distributions in the experiment: a Base distribution (B), a High distribution (H), a Low distribution (L), ${ }^{6}$ a Stabilized distribution (S), and a Truncated distribution (T). To control for potential ordering effects, these five distributions were offered to farmers in one of four orderings: [B-S-T-H-L-B], [B-L-T-H-S-B], [B-T-L-S-H-B], and [B-H-S-L-T-B]. Since farmers' valuation of distribution changes are desired, these orderings focus attention on changes

\footnotetext{
${ }^{5}$ When questioned about this tendency, most expressed a distinct preference for playing the game over not playing the game. Some associated this preference with their proclivities as farmers, explaining that a farmer who fails to plant seed in a given season is certain not to succeed. For others, the preference to play was simply due to playing being more enjoyable than not playing. Whatever the explanation, it is clearly important to control for this game effect before interpreting farmers' WTP.

${ }^{6}$ To simplify the presentation I exclude the $L$ distribution and focus just on the $B, H, S$, and T distributions for part of the analysis in the paper.
} 
relative to the Base distribution, B. Throughout, I use the average of farmers' high-stakes WTP for the first B and the second B to represent W'TP for B. These four distributions were preceded by two simplified practice distributions to allow farmers to understand the structure of the experiment.

During the experiment, each enumerator worked separately with at most two farmers. If an enumerator was working with two farmers, they would be seated far enough apart that their conversations with the enumerator, including any questions about the experiment and the farmers' stated WTP, were completely private. Logistically, the experiment was typically held in a public room in the village and would last approximately two hours. The first hour was spent explaining and practicing the experiment, then tea was served and farmers could discuss the experiment among themselves. The second hour was spent on the B, H, L, S, and T distributions. At the conclusion of the experiment, the enumerators asked farmers how well they had understood the experiment, to which 11\% reported 'with some confusion,' 4\% reported 'poorly', and $0 \%$ reported 'very poorly.' Enumerators verified this high degree of comprehension through individual and collective interaction with the farmers.

Figure 3 shows the marginal (top panel) and cumulative (bottom panel) probability distributions for the $\mathrm{B}, \mathrm{H}, \mathrm{S}$, and $\mathrm{T}$ distributions of the experiment (note that the $\mathrm{L}$ distribution that is excluded here is B shifted down Rs30). The top panel also shows the Expected Value (EV), standard deviation $(\sigma)$ and skewness (sk) of each distribution. These simple typological distributions where chosen to facilitate farmers' understanding of the experiment. As described above, we used a large board with simplified pictures similar to those in Figure 3 (without EV, $\sigma$ and sk) to explain each distribution to farmers. These distributions were also chosen so that key hypotheses about farmers valuation of higher moments of yield distributions could be tested. Specifically, these distributions represent an increase in $\mathrm{EV}$ that leaves $\sigma$ and skewness unchanged $(\mathrm{H})$, a decrease in $\sigma$ that leaves EV and skewness unchanged (S), and an increase EV due to an increase in skewness that leaves $\sigma$ relatively unchanged $(\mathrm{T})$. From the cumulative probability distributions in the bottom panel 
of Figure 3, the first-order stochastic dominance $\left(>_{\mathrm{FSD}}\right)$ properties of these distributions are: $\mathrm{H}>_{\mathrm{FSD}} \mathrm{B}, \mathrm{T}>_{\mathrm{FSD}} \mathrm{B}, \mathrm{T}>_{\mathrm{FSD}} \mathrm{S}$. S weakly second-order stochastic dominates $\mathrm{B}\left(\mathrm{S} \geq_{\mathrm{SSD}} \mathrm{B}\right)$. There is no dominance relationship for $\mathrm{H}, \mathrm{T}$ and $\mathrm{H}, \mathrm{S}$.

Descriptive Statistics: Table 1 contains descriptive statistics for several relevant variables from the questionnaire and experiment. Of the 290 farmers surveyed, only three (or 1\%) are female. One third of the farmers have no formal education and the average farmer has five years. 33\% (73\%) own a television (radio), but only 4\% own a tractor. Livestock are important for farmers in the survey area, and most farmers have at least a couple of animals. ${ }^{7}$ The average farmer farms five or six acres, about a third of which is irrigated. Cotton and maize are the two most important crops in terms of the percentage of farmers' land planted. Farmers' top ranking management goal is, not surprisingly, increasing yield, after which come protecting against pest losses and lowering production costs. Stabilizing yield across years and increasing harvest quality are relatively less important to the average farmer. Finally, farmers' WTP for B and S appear surprisingly indistinguishable for the average farmer, whose WTP is notably higher for T and H. Most farmers earned more than Rs60 in the experiment and none earned less than Rs40. Compared to the daily wage for unskilled labor in the survey site of about Rs50 the experiment payoffs provided non-trivial incentives.

Since the focus of this paper is farmers' valuation of changes in payoff distributions, additional descriptive statistics on farmers' bids in the experiment are insightful. One can describe these bid data graphically by sorting the bids for each distribution in descending order and then graphing these ordered data. Such a graph represents a simple demand curve. Graphs of the ordered bid data are shown in Figure 4. The purchase decision in the experiment was discrete, not

\footnotetext{
${ }^{7}$ Tropical Livestock Units are constructed as a weighted sum of cows, bullocks and goats, where the weights are 1, 1 and 0.1 , respectively.
} 
continuous, by construction so that farmers either purchased the seed or did not. Thus the horizontal axis in Figure 4 is the number of farmers who purchased a particular seed at a given price.

Consider first the curve for the Base (B) distribution with $\mathrm{EV}_{\mathrm{B}}=\mathrm{Rs} 50$. Ignoring the upper and lower tails of the curve, this curve has a shallow slope centered on the Rs45 mean bid (Table 1). The demand curve for B is nearly indistinguishable from the demand curve for S. This is surprising since $\mathrm{EV}_{\mathrm{B}}=\mathrm{EV}_{\mathrm{S}}=\mathrm{Rs} 50$ but $\sigma_{\mathrm{S}}=23.8<40.8=\sigma_{\mathrm{B}}$. This preliminary evidence suggests that farmers may not value lower yield variance. The demand curve for $\mathrm{T}$ is uniformly higher than both the $\mathrm{S}$ and $\mathrm{B}$ curves, and the curve for $\mathrm{H}$ is uniformly the highest curve. This confirms that farmers are indeed responsive to EV changes, but one can infer little more about farmers' valuation of distribution changes from these curves. Consider the difference between the curves of B and T. While it is clear that farmers are willing to pay a premium for $\mathrm{T}$, it is not clear whether this premium is a function of all three moment changes - a higher $\mathrm{EV}$, a lower variance and a higher skewness $\left(\mathrm{sk}_{\mathrm{T}}=1>0=\mathrm{sk}_{\mathrm{B}}\right.$, implying lower downside risk) - or only of a higher EV. To assess how these higher moments affect farmers' valuation, one must move beyond descriptive statistics.

\section{ANALYSIS}

In the econometric analysis that follows, I focus on three sets of models. The first set focuses on 'treatment' effects and estimates the mean valuation of the typological distributions of the experiment, both independently and relative to distribution B. The second set of models focuses on 'moment effects' and estimates farmers' valuation of moments of the payoff distributions. The third set of models focuses on 'farmer' effects and estimates how farmer traits affect farmers' valuation of payoff moments. This third set of models requires wealth and risk exposure indices, which I also discuss and estimate in this section. 
Treatment Effects Models: The models that isolate the treatment effects are of the form:

$$
W T P_{i t}=f\left(\mathbf{t}_{\mathbf{t}}, \mathbf{g}_{\mathbf{i t}}, \mathbf{f}_{\mathbf{i}}\right)+\varepsilon_{i t}
$$

where $W T P_{i t}$ is farmer is high-stakes bid or willingness-to-pay for distribution $t, \mathbf{t}_{\mathrm{t}}$ is a vector of treatment dummies with a 1 corresponding to distribution $t$ and 0's elsewhere, $\mathbf{g}_{\text {it }}$ is a vector of 'game effect' variables that control for the (artificial) effects of specific features of the experiment on bidding behavior, $\mathbf{f}_{\mathrm{i}}$ is a vector of farmer dummies with a 1 corresponding to farmer $i$ that controls for farmer fixed effects so that treatment effects are isolated, ${ }^{8}$ and $\varepsilon_{i t}$ is an error term distributed $N\left(0, \sigma_{\varepsilon i}^{2}\right)$ where the disturbance variance $\sigma_{\varepsilon \mathrm{i}}^{2}$ allows for heteroscedasticity between (but not within) farmers.

I consider three specifications of this generic treatment effects model. The first is:

$$
W T P_{i t}=\alpha_{B}+\alpha_{H} H_{t}+\alpha_{S} S_{t}+\alpha_{T} T_{t}+\alpha_{1} \text { Play }_{i t}+\alpha_{2} \text { Earn }_{i t}+\boldsymbol{\varphi}_{1}^{\prime} \mathbf{f}_{\mathbf{i}}+\varepsilon_{i t}
$$

which uses farmers' absolute WTP as the dependent variable. Independent variables consist of a constant, treatment dummies $(H, S, T)$, two 'game effects' variables (Play and Earn, explained below), and farmer fixed effects (f). The coefficients on the constant and on the treatment dummies are the coefficients of primary interest. The coefficient $a_{B}$ indicates the conditional mean WTP for B, and $\left(a_{B}+a_{H}\right),\left(a_{B}+a_{S}\right)$ and $\left(a_{B}+a_{T}\right)$ indicate the conditional mean WTP for $\mathrm{H}, \mathrm{S}$ and T, respectively. The first game effects variable (Play ${ }_{i t}$ ) is a 'play' dummy variable that is 1 if the farmer's bid in the practice season immediately preceding the high-stakes season of treatment $t$ was such that he purchased the seed (i.e., his bid was greater than or equal to the randomly drawn seed cost) and received an uncertain payoff. The second game effect variable (Earn $i$ ) captures the farmer's earnings in the immediately-preceding season.

\footnotetext{
${ }^{8}$ Recall that there are two high-stakes bids for $\mathrm{B}$ and one high-stake bid for $\mathrm{H}, \mathrm{S}$, and T elicited from each farmer.
} 
In expected utility parlance, the conditional mean WTP estimates $-a_{B},\left(a_{B}+a_{H}\right),\left(a_{B}+a_{S}\right)$, and $\left(a_{B}+a_{T}\right)$ for $\mathrm{B}, \mathrm{H}, \mathrm{S}$, and T, respectively - represent the corresponding mean certainty equivalents. ${ }^{9}$ Furthermore, the mean risk premium is approximately the difference between the EV and WTP for these distributions and can be computed as $\mathrm{RP}_{\mathrm{B}}=50-a_{B}, \mathrm{RP}_{\mathrm{H}}=80-\left(a_{B}+a_{H}\right), \mathrm{RP}_{\mathrm{S}}=50-\left(a_{B}+a_{S}\right)$, and $\mathrm{RP}_{\mathrm{T}}=65-\left(a_{B}+a_{\mathrm{T}}\right)$, respectively. The joint null hypothesis that tests for risk neutrality based on EV is therefore:

$$
\begin{aligned}
& \mathrm{H} 1_{0}: a_{B}=50=\mathrm{EV}_{\mathrm{B}} \quad \mathrm{H} 1_{\mathrm{A}}: \quad a_{\mathrm{B}}<50 \quad \text { [joint } \mathrm{EV} \text { risk neutrality] } \\
& a_{S}=0=\Delta \mathrm{EV}_{\mathrm{S}} \quad a_{S}>0 \\
& a_{H}=30=\Delta \mathrm{EV}_{\mathrm{H}} \quad a_{\mathrm{H}}<30 \\
& a_{T}=15=\Delta \mathrm{EV}_{\mathrm{T}} \quad a_{T}<15
\end{aligned}
$$

where $\Delta \mathrm{EV}_{\mathrm{t}}=\mathrm{EV}_{\mathrm{t}}-\mathrm{EV}_{\mathrm{B}}$.

Stochastic dominance detection is an important heuristic in the process of decision making under uncertainty (Kahneman and Tversky 1979). ${ }^{10}$ Dominance detection can be tested easily with this specification. Based on the first-order stochastic dominance $\left(>_{\mathrm{FSD}}\right)$ relationships $\mathrm{T}>_{\mathrm{FSD}} \mathrm{B}$, $\mathrm{T}>{ }_{\mathrm{FSD}} \mathrm{S}$, and $\mathrm{H}>_{\mathrm{FSD}} \mathrm{B}$, the following joint hypothesis tests for the detection of FSD:

$$
\begin{aligned}
& \mathrm{H} 2_{0}: a_{T}=0 \quad \mathrm{H} 2_{\mathrm{A}}: \quad a_{T}>0 \quad \text { [FSD detection] } \\
& a_{T}=\alpha_{S} \quad a_{T}>a_{S} \\
& a_{H}=0 \quad a_{H}>0
\end{aligned}
$$

The hypothesis that tests for lower variance valuation simultaneously tests for detection of weak second-order stochastic dominance:

$$
\mathrm{H} 3_{0}: \quad a_{S}=0 \quad \mathrm{H} 3_{\mathrm{A}}: \quad a_{S}>0 \quad \text { [lower variance valuation] }
$$

which tests whether farmers are willing to pay a premium for a decrease in variance that is isolated from a change in EV.

The second and third specifications that focus on treatment effects differ only in their dependent variable:

\footnotetext{
${ }^{9}$ Since the experimental distributions are over Rupee payoffs, this is true provided second order effects involving u'(.) are relatively small.
} 


$$
\begin{aligned}
\Delta W T P_{i t} & =\delta_{S}+\delta_{H} H_{t}+\delta_{T} T_{t}+\delta_{1} \operatorname{Earn}_{i t}+\boldsymbol{\varphi}_{2}^{\prime} \mathbf{f}_{i}+\varepsilon_{i t} \\
\Delta w t p_{i t} & =\delta_{S}^{\circ}+\delta_{H}^{\circ} H_{t}+\delta_{T}^{\circ} T_{t}+\delta_{1}^{\circ} \operatorname{Earn}_{i t}+\boldsymbol{\varphi}_{3}^{\prime} \mathbf{f}_{\mathbf{i}}+\varepsilon_{i t}
\end{aligned}
$$

where $\Delta$ indicates farmer $i$ s incremental willingness-to-pay for distribution $t$. In order to infer a farmer's valuation of changes in a yield distribution, we must assess how much more the farmer is willing to pay for one distribution over another. The experiment instructions deliberately cast distribution $\mathrm{B}$ as the benchmark distribution and $\mathrm{H}, \mathrm{S}$ and $\mathrm{T}$ as modifications of this benchmark, making the relevant increment the difference between a farmer's bid for B and his bid for $\mathrm{H}, \mathrm{S}$ and T. Thus, $\Delta W T P_{i t}=W T P_{i t}-\operatorname{avg}\left[W T P_{i B}\right]$ and $\Delta w t p_{i t}=\Delta W T P_{i t} / \operatorname{avg}\left[W T P_{i B}\right] \cdot{ }^{11}$ Using $\Delta W T P_{i t}$ and $\Delta w t p_{i t}$ instead of $W T P_{i t}$ as the dependent variable properly focuses the analysis on farmer-specific, incremental valuation of changes in yield distributions.

The estimated constant in these specifications represents the mean $\Delta W T P$ or $\Delta w t p$ for $\mathrm{S}$. Thus, $\left(\delta_{S}+\delta_{H}\right)$ and $\left(\delta_{S}{ }^{\circ}+\delta_{H}\right)$ represent the mean $\Delta W T P$ and $\Delta w t p$ for $\mathrm{H}$, and $\left(\delta_{S}+\delta_{T}\right)$ and $\left(\delta_{S}{ }^{\circ}+\delta_{T}{ }^{g}\right)$ represent the mean $\triangle W T P$ and $\Delta w t p$ for $\mathrm{T}$. Hypotheses for testing risk neutrality and dominance detection with these specifications are simple extensions of $\mathrm{H} 1$ and $\mathrm{H} 2$ above. Hypotheses for testing variance and skewness valuation are also natural extensions of $\mathrm{H} 3$ and $\mathrm{H} 4$ but merit explicit statements:

$$
\begin{aligned}
& \mathrm{H} 3_{0}{ }^{\prime}: \quad \delta_{S}=0 \quad \mathrm{H} 3_{\mathrm{A}}{ }^{\prime}: \quad \delta_{S}>0 \quad[\Delta \text { valuation due to lower var. }] \\
& \mathrm{H} 3_{0}{ }^{\prime \prime}: \quad \delta_{S}{ }^{\circ}=0 \quad \mathrm{H} 3_{\mathrm{A}}{ }^{\prime \prime}: \quad \delta_{S}{ }^{\circ}>0 \quad[\% \Delta \text { valuation due to lower var. }]
\end{aligned}
$$

In estimating these three treatment effect models, I assume that the variance of the disturbance term, $\sigma_{\mathrm{ei}}^{2}$, may be different for each farmer $i$. That is, the estimation of these models imposes homoscedasticity within farmers but allows for heteroscedasticity between farmers. In general, allowing for heteroscedasticity between farmers is appealing for the same reasons farmer

\footnotetext{
${ }^{10}$ Dominance heuristics are especially important in the 'editing stage' of the decision-making process in which an individual simplifies the problem he faces (Kahneman and Tversky 1979).
} 
fixed-effects are appealing. To illustrate more specifically why different farmers likely have different $\sigma_{\mathrm{si}}^{2}$, consider some farmers' tendency to bid in Rs5 increments. Though the experiment imposed no restrictions on farmers' bids, about one third of the farmers bid exclusively in Rs 5 increments (i.e., Rs35, 40, 45, etc.), one third bid mostly in Rs5 increments, and one third - undeterred by the 'roundness' of Rs5 increments - bid in increments of Rs1. Because his bids are more discretized, a farmer who bids exclusively in Rs5 increments almost surely has a larger $\sigma_{\mathrm{ei}}{ }^{2}$ than one who bids in Rs1 increments. ${ }^{12}$ White (1980) standard errors are thus computed throughout to allow for between, but not within, farmer heteroscedasticity.

Table 2 displays estimation results for these treatment effect models with farmer-fixed effects and standard errors corrected for within-farmer heteroscedasticity. The top panel displays results for all farmers. The bottom panel displays results for farmers who understood the experiment, which excludes the 16\% who reported they had understood the experiment 'with some confusion,' 'poorly' or 'very poorly.' At the 10\% level (one-sided), we reject the joint null of risk neutrality based on EV (H1) for all farmers and for those who understood. We also easily reject the null of FSD detection (H2) for both samples. Farmers clearly detected the obvious dominance relationships $\mathrm{T}>_{\mathrm{FSD}} \mathrm{B}, \mathrm{T}>_{\mathrm{FSD}} \mathrm{S}$, and $\mathrm{H}>_{\mathrm{FSD}} \mathrm{B}$. Based on the coefficients on $\mathrm{S}$, the test of lower variance valuation (H3) indicates that farmers' valuation of lower variance appears to be zero on average. This confirms statistically what is true graphically in Figure 4: the demand curves for S and

\footnotetext{
${ }^{11}$ Recall that in the experiment, farmers bid on $B$, then on the other distributions (in four different orderings), then again on B. Averaging farmers' initial high-stakes bid for B with their final high-stakes bid for B controls for changes in farmers' valuation of B that might have occurred as their understanding increases over the course of the experiment. ${ }^{12}$ An analog exists in domestic labor surveys: workers who report working 38 hours per week are generally reporting hours worked more accurately than those who report 40 hours per week, many of whom actually worked a few hours more or less than 40 hours. Whether this pull comes from a general preference for such increments (anecdotally, pricing in farmers' markets in the study site is often in Rs5 increments) or from the experiment itself, which specified all payoffs at even Rs10 increments, its presence is clear.
} 
$\mathrm{B}$ are indistinguishable. The risk premia in Table 2 are averages implied by the estimated mean WTP for each distribution. ${ }^{13}$

The results for the $\triangle W T P$ model indicate a failure to reject $H 3$ '. Indeed, whether all farmers or only farmers who understood are included $\delta_{S}$ is negative, implying that farmers actually pay less for the lower variance of S. That is, they seem to value the lower downside risk less than the potential upside gain they sacrifice to get it. Results from the $\Delta w$ tp model support this finding.

Moment Effects Model: The model that isolates farmers' valuation of the first three moments of payoff distributions is:

$$
W T P_{i t}=\alpha_{0}+\alpha_{E V} E V_{t}+\alpha_{S D} S D_{t}+\alpha_{S k} S k_{t}+\alpha_{1} \text { Play }_{i t}+\alpha_{2} \text { Earn }_{i t}+u_{i}+\varepsilon_{i t}
$$

where $\mathrm{EV}$ is expected value, $S D$ is standard deviation, $S k$ is skewness (a dummy variable for distribution T), $u_{i}$ is a farmer random effect, and $\varepsilon_{i t}$ is an error term distributed $N\left(0, \sigma_{\varepsilon}^{2}\right)$. This specification directly tests farmers' valuation of the first three moments of the payoff distribution. The hypothesis that tests farmers' valuation of higher skewness is simply:

$$
\mathrm{H} 4_{0}: a_{S k}=0 \quad \mathrm{H} 4_{\mathrm{A}}: a_{S k}>0 \quad \text { [higher skewness valuation] }
$$

As above, I estimate two additional moment effects models to capture farmers' incremental valuation of moments of the payoff distributions.

$$
\begin{aligned}
& \Delta W T P_{i t}=\alpha_{0}+\alpha_{E V} E V_{t}+\alpha_{S D} S D_{t}+\alpha_{S k} S k_{t}+\alpha_{1} E_{a r n}+u_{i}+\varepsilon_{i t} \\
& \Delta w t p_{i t}=\alpha_{0}+\alpha_{E V} E V_{t}+\alpha_{S D} S D_{t}+\alpha_{S k} S k_{t}+\alpha_{1} \text { Earn }_{i t}+u_{i}+\varepsilon_{i t}
\end{aligned}
$$

To identify the coefficients on the moment variables in these specifications, I must include the $\mathrm{L}$ distribution (because the $\mathrm{B}$ distribution is excluded in the estimation of these incremental

\footnotetext{
${ }^{13}$ Farmers' maximum WTP for each payoff distribution is defined as $u(w)=\mathrm{E} u(w+y$-WTP) where $w$ is wealth and $y$ is the yield payoff. The risk premium (RP) is defined as $R P=E y-C E$, where $C E$ is the certainty equivalent defined as $u(w+\mathrm{CE})=\mathrm{E} u(w+y)$. As long as second order effects in the function $u($.$) are relatively small WTP \approx \mathrm{CE}$ and $\mathrm{RP} \approx \mathrm{E} y-$ WTP.
} 
specifications). To allow comparisons between these two specifications and the total WTP specification, I estimate the W'TP model first excluding then including the L distribution.

Estimation results for these moment-effects models are shown in Table 3. On average, farmers value Rs1 of EV at Rs0.44, but value neither lower variance nor higher skewness. This result is confirmed for both total and incremental valuation and is robust to the inclusion of all farmers or only those who understood the experiment well.

Wealth and Risk Exposure Indices: The third set of models focus on farmer characteristics and require wealth and risk exposure indices, which I discuss and estimate in this subsection. The wealth index is the product of a vector of farmer wealth variables $\left(\mathbf{w}_{\mathbf{i}}\right)$ and a vector of corresponding weights $\left(\boldsymbol{\gamma}_{\mathrm{w}}\right)$. The risk exposure index is analogously the product of a vector of farmer risk exposure variables $\left(\mathbf{r}_{\mathbf{i}}\right)$ and a vector of corresponding weights $\left(\boldsymbol{\gamma}_{\mathbf{R}}\right)$. These scalar indices of farmer wealth and risk exposure are thus:

$$
\begin{aligned}
\text { Wealth } & =\gamma_{\mathbf{W}}^{\prime} \mathbf{w}_{\mathbf{i}} \\
\text { Risk }_{i} & =\boldsymbol{\gamma}_{\mathbf{R}}^{\prime} \mathbf{r}_{\mathbf{i}}
\end{aligned}
$$

To estimate $\gamma_{\mathrm{W}}$ and $\gamma_{\mathrm{R}}$, I use factor analysis so that the data determine the weights. ${ }^{14}$ The results of this estimation approach are shown in Table 4.

The asset variables used in the wealth index include acres of non-irrigated land, Tropical Livestock Units (TLU, includes bullocks, cows and goats with weights 1, 1 and 0.1 , respectively), television ownership, and ownership of a house with a concrete floor. Total expenses includes the total annual expenses (Rs) on clothes, education, electronics, and medicine and is meant to capture expenses that vary significantly across households according to wealth, rather than a complete

\footnotetext{
${ }^{14}$ I follow an iterative approach for selecting the variables included in $\mathbf{w}_{\mathbf{i}}$ and $\mathbf{r}_{\mathbf{i}}$. Beginning with a broad set of variables, I estimate an initial weight vector and compute a residual correlation matrix. When off-diagonal residual correlation is greater than 0.10 between two variables, I retain the variable that seems to be more relevant or more reliable and remove the other, then re-estimate the weight vector using this more focused variable vector. See Lawley
} 
accounting of household expenses. The coefficients and means shown in Table 4 suggest that total expenses and acres of non-irrigated land contribute the most to the average farmer's wealth index. Table 4 also shows hypotheses that test the existence of a common factor and whether more than one is needed. ${ }^{15}$ Given the variables included in the wealth index, these tests suggest there is clearly a single common factor.

Wealth is generally a well-defined - if imperfectly measured - characteristic that researchers can reasonably hope to approximate with a scalar index. Capturing a farmer's or farm household's exposure to risk, on the other hand, poses an admittedly greater challenge. Others have computed related measures of vulnerability and risk exposure. Maxwell (1996) and Maxwell et al. (1999) construct a food insecurity index based on the frequency and severity of a household's responses to food shortages. Thus computed, the index captures the household's vulnerability to fluctuations in its food supplies. Mosely (2003), who also uses an experimental approach, constructs an index of 'perceived vulnerability' based inter alia on an individual's memory and expectation of poverty to capture individual's attitude towards risk.

The risk exposure index I compute aims to capture exposure primarily to agricultural production risk. The index is based on the recent income and crop fluctuations experienced by farmers, their own perceptions about the riskiness of their income sources, and their ability to insulate themselves from drought through access to irrigation. The survey asked farmers to recall the worst farming season they had experienced in the last five years and to describe the causes and consequences of this particular season, including which crop was most severely affected. The first variable in the risk index indicates the percent of this crop that was lost in this particular season. The survey also asked farmers to list their three most important productive activities and how much of their total income came from each activity. The second and third variables, respectively, indicate the

and Maxwell (1971) for details about factor analysis. See Sahn et al. (1999) and Lybbert et al. (2002) for applications of factor analysis that involve asset and wealth indices similar to those constructed in this section. 
percent of a farmer's total income that comes from what he perceives to be 'very risky' and 'no risk' sources. The fourth variable is acres of irrigated land owned by the farmer.

The results in Table 4 suggest that the percent income from 'very risky' sources contributes the most to the average farmer's risk exposure index. Percent income from 'no risk' sources and total irrigated land reduce a farmer's risk exposure. Surprisingly, the percent crop lost in the worst season in five years also reduces a farmer's current risk exposure, suggesting either that the variable is measured with error or that farmers who were hard hit in a recent bad season have since altered their productive strategies to reduce their exposure. Hypothesis tests again confirm that there exists a single common factor.

The left panel of Figure 5 displays kernel density plots of the wealth and risk exposure indices. ${ }^{16}$ The right panel of Figure 5 displays a scatter plot of the two indices with a kernel density regression line of the wealth index on the risk exposure index. ${ }^{17}$ These two indices are clearly uncorrelated (correlation coefficient -0.06).

Farmer Effects Models: With wealth and risk exposure indices in hand, I now discuss and estimate farmer effects models. These farmer effects model seek to understand differences between farmers in their valuation of seed traits. Do farmers with different characteristics value higher moments of yield distributions differently? This set of models seeks to shed some light on this question, which has important implications for the likely valuation and uptake of pro-poor seeds that confer primarily higher moment benefits. These models share the form:

$$
W T P_{i j t}=f\left(\mathbf{m}_{\mathbf{t}}, x_{1 i} \mathbf{m}_{\mathbf{t}}, \ldots, x_{N i} \mathbf{m}_{\mathbf{t}}, \mathbf{z}_{\mathbf{i}}, \mathbf{g}_{\mathrm{it}}, \mathbf{v}_{\mathbf{j}}\right)+u_{i}+\varepsilon_{i j t}
$$

where $\mathbf{m}_{\mathbf{t}}$ is again a vector of the first three moments of payoff distributions (i.e., EV, standard deviation, skewness), $x_{1\rangle}, \ldots, x_{N i}$ are scalar farmer characteristics so that $\chi_{n i} \mathbf{m}_{\mathbf{t}}$ is a vector of farmer-

\footnotetext{
${ }^{15}$ These tests are possible because the coefficients were estimated using maximum likelihood.
} 
moment interaction variables, $\mathbf{z}_{\mathbf{i}}$ is a vector of (un-interacted) farmer characteristics, $\mathbf{g}_{\mathbf{i t}}$ is again a vector of game effect variables, $\mathbf{v}_{\mathbf{j}}$ is a vector of village dummies, $u_{i}$ is a farmer random effect, and $\varepsilon_{i t}$ is an error term distributed $N\left(0, \sigma_{\varepsilon}^{2}\right)$. Instead of fixed- or random-effects, farmer effects are now modeled explicitly using farmer-specific variables. Consider the following specification:

$$
\begin{aligned}
W T P_{i j t} & =\beta_{0}+\boldsymbol{\beta}^{\mathbf{t}^{\prime}} \mathbf{m}_{\mathbf{t}}+\boldsymbol{\beta}^{\mathbf{w}^{\prime}} \text { Wealth }_{i} \mathbf{m}_{\mathbf{t}}+\boldsymbol{\beta}^{\mathbf{R}^{\prime}} \text { Risk }_{i} \mathbf{m}_{\mathbf{t}}+\boldsymbol{\beta}^{\mathbf{B t}^{\prime}} \text { Bt }_{i} \mathbf{m}_{\mathbf{t}}+\boldsymbol{\beta}^{\mathbf{M}^{\prime}} \text { MisUnd }_{i} \mathbf{m}_{\mathbf{t}} \\
& +\beta_{1} \operatorname{IrrL}_{i}+\beta_{2} \text { Edu }_{i}+\beta_{3} \text { Age }_{i}+\beta_{4} \text { Play }_{i t}+\beta_{5} \text { Earn }_{i t}+\mathbf{v}^{\prime} \mathbf{v}_{\mathbf{j}}+u_{i}+\varepsilon_{i t}
\end{aligned}
$$

where $W$ ealth $h_{i}$ is the wealth index for farmer $i, R_{i s k}$ is the risk exposure index, ${ }^{18} B t_{\mathrm{i}}$ is a dummy variable that is 1 if farmer $i$ has adopted $B t$ cotton and 0 otherwise, MisUnd is 1 if farmer $i$ understood the experiment with 'some confusion,' 'poorly' or 'very poorly' and 0 otherwise, $\operatorname{Irr}_{i}$ is acres of irrigated land cultivated, $E d u_{i}$ is years of education, $A g e_{i}$ is age in years, and all other variables are as defined above. Coefficient vectors (e.g., $\boldsymbol{\beta}^{\mathrm{t}}$ ) are indicated in bold.

As before, I estimate two additional specifications of this model $-\Delta W T P$ and $\Delta w t p-$ that focus on farmers' incremental valuation. I estimate both of these specifications with the $\mathrm{L}$ distribution included. Again, I estimate the W'TP specification first excluding then including the L distribution to ensure comparability. Table 5 displays the estimation results for these three specifications. Consistent with the previous results, farmers appear to value only expected value and not lower variance or higher skewness. Wealthy farmers appear to value lower variance less than poor farmers. The magnitude of this wealth effect for $\mathrm{H}$ is even higher in the $\triangle W T P$ and $\triangle w t p$ models. Wealth does not appear to affect farmers' valuation of skewness, which remains statistically zero.

The only risk exposure variable that is close to statistical significance at the $10 \%$ level is the skewness interaction variable ( $\mathrm{p}$-values are $0.13,0.11,0.26$ for the $W T P, \Delta W T P$, and $\Delta w t p$ models,

\footnotetext{
${ }_{17}^{16}$ Epanechnikov kernel with bandwidths of 0.18 and 0.17 , respectively.

17 Logistic kernel with bandwidth of 0.13 .
} 
respectively). ${ }^{19}$ Thus, there is weak evidence that farmers exposed to greater risks value a reduction in downside risk more than those exposed to less risk. The mean of the highest (lowest) quintile of the risk index is $0.76(-0.79)$. Thus, the (Risk $\mathbf{x}$ Skew $)$ coefficient in the $\Delta W T P$ model $(\mathrm{p}=0.11)$ implies a difference in the incremental valuation of the highest and lowest quintiles of about Rs4.5.

Bt cotton farmers appear to value lower variance slightly more than other farmers, although these effects are not strongly significant. Farmers who indicated they understood the experiment with 'some confusion,' 'poorly' or 'very poorly' seem to value EV substantially and significantly less than those who understood the experiment well. These misunderstand variables are meant, however, to control for farmers' valuation, rather than explain it.

Overall, these results suggest that, relative to wealthy farmers, poor farmers do not appear to value higher skewness of a distribution, but may value lower variance. The imprecision of the estimates, however, makes this evidence weak at best. Generally, while farmers are clearly not identical in their valuation of these experimental distributions, there are no clear patterns that connect farmer traits to valuation. These results reinforce the conclusion from the treatment effects models that farmers are more responsive to changes in EV than in variance or skewness.

\section{DISCUSSION}

One of the objectives of this paper is to explore the use of an experimental methodology in empirical development economics. While the presentation of this paper's motivation, the experimental design and the analysis of the experimental data have helped to explore this methodology, the objective requires a more explicit discussion of the limitations of the experiment used in this paper. Some of these are general limitations to experimental economics. Others are

\footnotetext{
${ }^{18}$ While the risk exposure index possibly introduces an endogeneity problem, there are no good instruments available for this index. This problem, which admittedly may bias the estimation results, arises because a farmer who chooses risky activities as his income sources may bid more for a risky payoff.
} 
design-dependent and might be remedied through modifications in the experiment - albeit often at the cost of new limitations. This section discusses some of these limitations of the experiment used in this paper and highlights a few of these design tradeoffs. Any practical implications of the results in this paper should be informed by an understanding of these limitations.

As mentioned, a major challenge in designing the experiment was striking an appropriate balance between context and abstractness. The experiment was situated clearly in a farm context, but payoff distributions were kept abstract. Keeping the distribution independent from any particular seed or seed trait has the advantage of focusing farmers' attention on general yield risk. This abstraction, however, ignores more qualitative features of farmers' risk preferences. For example, would farmers have responded differently if they were told the truncation in a yield distribution was due to pest-resistance or drought-tolerance? Farmers might be notably more risk averse under the specific (and feared) threat of pests or drought. Ignoring these qualitative dimensions to risk perception might produce underestimates of farmers' valuation of pest-resistant or drought-tolerant seeds. On the other hand, formally introducing qualitative features of yield risk may also complicate the experiment and confuse farmers. Further research is needed to assess the relative importance of farmers' perceptions and valuation of qualitative yield risk.

Another limitation due to abstraction relates to how farmers make farm-level decisions about seeds and other productive and managerial inputs. In practice, these decisions are iterative and collective. Farmers generally interact extensively with other farmers, agro-services dealers and family members as they formulate their input purchasing decisions. In this experiment, farmers made valuation decisions individually and privately. The experiment did, however, offer farmers several practice rounds with each payoff distribution. So, while the design included some iteration in the decision process, it did not allow for consultation with others.

\footnotetext{
${ }^{19}$ Keep in mind, however, that the estimated risk exposure coefficients are potentially biased due to the possible endogeneity of the risk index.
} 
Next, the design of the experiment used in this paper may suit cash crop farmers, but may be inappropriate for subsistence farmers. Since this limitation stems from the use of monetary payoffs, a modified experiment involving in-kind payoffs might make the experiment amenable to subsistence farmers. With such a modification, it is possible that these farmers, for whom subsistence thresholds may be particularly threatening, would display markedly different risk preferences and would value risk-reducing seeds quite differently than cash crop farmers. While this may be an important general concern, most of the farmers in this experiment grow cash crops.

Another possible limitation is that relatively wealthy farmers may not have treated the experiment as seriously as their poorer neighbors. A farmer's total expected payoff was intentionally designed to be higher than the daily wage rate for unskilled labor - a considerable amount for a poor farmer, but obviously less substantial for a wealthy one. Still, in experimental economics, even small payoffs can provide substantial incentives to participants (Davis and Holt 1993). Given the setting of the experiment, a more likely problem with wealthy farmers is that they may not be all that different from poor farmers. Even wealthy farmers are only wealthy relative to other farmers in their village and are in fact poor relative to wealthy farmers in other Indian states may help to explain why relative wealth does not significantly influence farmers' W'TP.

A deeper limitation of using experiments to elicit farmers' valuation of risk-reducing seeds is that the researcher cannot ethically expose farmers to substantial risks such as crop failure due to pests. The experiment conducted in this project was designed so that farmers might lose a few Rupees in a particular round but would always leave the experiment with positive net earnings. While this is an ethical necessity, it is also an important limitation to any study of downside risk preferences. Farmers' valuation of the higher moments of a payoff distribution would surely be more effectively elicited by an experiment that offers farmers gambles with the risk of substantial loses. Of course, such experiments are ethically inappropriate. Small short-term loses in an experiment are generally permissible only if subjects' total net earnings are positive. Such a guarantee 
of net gain may introduce moral hazard problems that lead farmers to unrealistic behavior. After all, an experiment that lacks substantial risk of loss can hardly simulate the kinds of livelihood risks that farmers in poor countries often face. As a possible remedy, a modified experiment could frame short-term loses within a round such that they are perceived as more significant longer-term loses.

Ultimately, the relevant question here is whether farmers' decisions in the experiment differed systematically from decisions they would make on the farm. Answering this question will require additional research into the use of economic experiments among farmers in developing countries. The growing body of research using field experiments in developing countries (see Cardenas and Carpenter 2004) offers encouragement for such research. The present experiment contributes to this encouragement. The limitations above represent what I think are this experiment's most serious limitations. Conspicuously missing from this list is farmer confusion. Based on pre-testing of the experiment, farmer practice with the experiment, farmers' selfassessments, and informal follow-up discussion with farmers, I am confident that most farmers understood the experiment remarkable well. That this is true for farmers with little or no formal education and despite a relatively complex experimental design is encouraging. In particular, this suggests that even relatively involved experimental designs that allow for iterative learning and openended valuation questions may be viable options for researchers working among those with little or no formal education. If this degree of comprehension is possible in other settings, several challenging and policy-relevant research questions might be addressed in the future through experimental methods.

\section{CONCLUSIONS}

The analysis of this paper suggests that farmers are generally more responsive to changes in the expected value $(\mathrm{EV})$ of a yield distribution than in the higher moments of the distribution. The 
farmers surveyed appear to value neither lower variance nor higher skewness even though both are presumably favorable for any risk-averse farmer. There are some loose patterns in farmers' valuation. For example, wealthy farmers appear to value increases in $\mathrm{EV}$, but poor farmers may value a decrease in variance more than the wealthy. Likewise, farmers who consider their sources of income to be quite risky value seem to value higher skewness in a payoff distribution, which implies lower downside risk, more than other farmers. But these findings are statistically weak and the results do not yield any strong conclusions about the effect of farmers' traits on their valuation of yield distribution properties. This suggests that farmers' constraint sets (e.g., access to credit and inputs) may determine their adoption of pro-poor seeds that reduce risk more than their risk preference-based valuation of these seeds (Binswanger 1980).

These results have implications for the development and delivery of pro-poor seeds that reduce yield risk. If farmers do not value a lower variance or higher skewness in a crop yield distribution, then seeds with stabilized or truncated yield distributions must be marketed based on other traits. Not surprisingly, the best trait breeders could include to sell a seed would be higher expected yield. In the end, the development and delivery of pro-poor seeds that reduce risk must be informed by farmers' valuation of quantitative yield risk, as explored in this paper, and qualitative dimensions of yield risk and threats such as drought and pests. A comprehensive assessment of farmers' valuation of risk-reducing seeds is necessary because adoption patterns might be distinctly different for such seeds given that the benefit of these seeds is stochastic and may be particularly difficult for farmers to discern. These benefits from these pro-poor seeds may also extend beyond farmers. For example, consumers facing poorly integrated food markets may benefit from riskreducing seeds since, in such cases, yield distributions offen shape the distribution of food prices.

As with any experiment, the one used in this paper has a variety of limitations. Although the experiment was set in a farming context, it could not fully capture the richness of farmers' actual seed selection and valuation decisions. Consequently, farmers' valuation of payoff distributions in 
the experiment may only partially represent their valuation of crop yield distributions. Despite these limitations, the experiment encouragingly suggests that farmers with little or no formal education can comprehend experiments that allow for iterative learning through repeated rounds and elicit valuation through open-ended questions using standard laboratory techniques. This raises the possibility of using experimental economics to address a variety of other policy-relevant questions in development economics. 


\section{REFERENCES}

Adesina, A. A., and J. Baidu-Forson. "Farmers' Perceptions and Adoption of New Agricultural Technology: Evidence from Analysis in Burkina Faso and Guinea, West Africa." Journal of Agricultural Economics 13(1995): 1-9.

Balistreri, E., et al. "Can Hypothetical Questions Reveal True Values? A Laboratory Comparison of Dichotomous Choice and Open-Ended Contigent Values with Auction Values." Environmental and Resource Economics 18(2001): 275-292.

Banerjee, A. (2004) The Two Poverties, ed. S. Dercon. Oxford, Oxford University Press.

Barrett, C. B., M. Bezuneh, and A. Aboud. "Income Diversification, Poverty Traps and Policy Shocks in Cote d'Ivoire and Kenya." Food Policy 26, no. 4(2001): 367-84.

Batz, F. J., K. J. Peters, and W. Janssen. "The Influence of Technology Characteristics on the Rate and Speed of Adoption." Agricultural Economics 21, no. 2(1999): 121-30.

Becker, D. E., M. H. DeGroot, and J. Marschak. "Measuring Utility by a Single-Response Sequential Method." Behavioral Science 9(1964): 226-232.

Binswanger, H. P. "Attitudes Toward Risk: Experimental Measurement in Rural India." American Journal of Agricultural Economics 62(1980): 395-407.

Binswanger, H. P. (1979) Risk and uncertainty in agricultural development: An overview, ed. J. A. Roumasset, J.-M. Boussard, and I. Singh.

Cameron, L. A. "The Importance of Learning in the Adoption of High-Yielding Variety Seeds." American Journal of Agricultural Economics 81, no. 1(1999): 83-94.

Cardenas, J. C., and J. P. Carpenter (2004) Experimental Development Economics. Middlebury College.

Carpenter, J. P., G. W. Harrison, and J. A. List (2005) Field Experiments in Economics, vol. 10. Greenwich, CT, JAI Press.

Carter, M. R., and J. May. "Poverty, Livelihood and Class in Rural South Africa." World Development 27, no. 1(1999): 1-20.

Conway, G. The doubly green revolution: food for all in the twenty-first century. London: Penguin, 1997.

Coursey, D. L., J. L. Hovis, and W. D. Schulze (1999) The Disparity between Willingness to Accept and Willingness to Pay Measures of Value, ed. K. G. Willis, K. Button, and P. Nijkamp, vol. 1.Methods and anomalies. Northampton, Mass., Elgar, pp. 304-15.

Cromwell, E., E. Friis-Hansen, and M. Turner. The seed sector in developing countries : a framework for performance analysis. London: Overseas Development Institute, 1992.

David, S., and L. Sperling. "Improving technology delivery mechanisms: Lessons from bean seed systems research in eastern and central Africa." Agriculture and Human V alues 16(1999): 381388.

Davis, D. D., and C. A. Holt. Experimental Economics. Princeton, N.J.: Princeton University Press, 1993.

Dercon, S. (2004) Insurance Against Poverty, Oxford University Press.

Dercon, S. "Wealth, Risk and Activity Choice: Cattle in Western Tanzania." Journal of Development Economics 55, no. 1(1998): 1-42.

DeVries, J., and G. H. Toenniessen. Securing the barvest : biotechnology, breeding, and seed systems for African crops. Wallingford, UK ; New York: CABI Pub., 2001.

Feder, G., R. E. Just, and D. Zilberman. "Adoption of Agricultural Innovations in Developing Countries: A Survey." Economic Development and Cultural Change 33, no. 2(1985): 255-98.

Foster, A. D., and M. R. Rosenzweig. "Learning by Doing and Learning from Others: Human Capital and Technical Change in Agriculture." Journal of Political Economy 103, no. 6(1995): 1176-1209.

Heisey, P. W., and J. P. Brennan. "An Analytical Model of Farmers' Demand for Replacement Seed." American Journal of Agricultural Economics 73, no. 4(1991): 1044-52. 
Holloway, G., et al. "Agroinducstrialization through institutional innovation: Transaction costs, cooperatives and milk-market development in the east-African highlands." Agricultural Economics 23(2000): 279-288.

Humphrey, S. J., and A. Verschoor. "Decision-making Under Risk Among Small Farmers in East Uganda." Journal of African Economies 13, no. 1(2004a): 44-101.

Humphrey, S. J., and A. Verschoor. "The probability weighting function: experimental evidence from Uganda, India and Ethiopia." Economics Letters 84, no. 3(2004b): 419-425.

Irwin, J. R., et al. "Payoff Dominance vs. Cognitive Transparency in Decision Marking." Economic Inquiry 36, no. 2(1998): 272-285.

Ismael, Y., R. Bennett, and S. Morse. "Benefits from Bt Cotton Use by Smallholder Farmers in South Africa." AgBioForum 5, no. 1(2002): 1-5.

Kahneman, D., and A. Tversky. "Prospect Theory: An Analysis of Decision under Risk." Econometrica 47, no. 2(1979): 263-91.

Lawley, D. N., and A. E. Maxwell. Factor analysis as a statistical method. 2nd ed. London,: Butterworths, 1971.

Lipton, M. "Reviving Global Poverty Reduction: What Role for Genetically Modified Plants?" Journal of International Development 13, no. 7(2001): 823-46.

Lipton, M. "The theory of the optimising peasant." Journal of Development Studies 4(1968): 327-351.

Lipton, M., and R. Longhurst. New seeds and poor people. The Johns Hopkins studies in development. Baltimore: Johns Hopkins University Press, 1989.

Louwaars, N. P., et al. Seed supply systems in developing countries. Wageningen, Netherlands: Technical Centre for Agricultural and Rural Cooperation: Wageningen Agricultural University, 1997.

Lybbert, T. J., et al. "Stochastic Wealth Dynamics and Risk Management Among a Poor Population." Economic Journal (2004).

Lybbert, T. J., C. B. Barrett, and H. Narjisse. "Market-Based Conservation and Local Benefits: The Case of Argan Oil in Morocco." Ecological Economics 41, no. 1(2002): 125-44.

Maxwell, D., et al. "Alternative Food-Security Indicators: Revisiting the Frequency and Severity of 'Coping Strategies '." Food Policy 24, no. 4(1999): 411-29.

Maxwell, D. G. "Measuring Food Insecurity: The Frequency and Severity of "Coping Strategies "." Food Policy 21, no. 3(1996): 291-303.

Mosley, P. (2003) Risk. Attitudes in the 'V icious Circle of Poverty'. University of Manchester.

Pitt, M. M., and G. Sumodiningrat. "Risk, Schooling and the Choice of Seed Technology in Developing Countries: A Meta-Profit Function Approach." International Economic Review 32, no. 2(1991): 457-73.

Pray, C. E., and K. O. Fuglie (2000) The Private Sector and International Technology Transfer, ed. K. O. Fuglie, and D. E. Schimmelpfennig. Ames, Iowa, Iowa State University Press, pp. 269299.

Qaim, M., and D. Zilberman. "Yield Effects of Genetically Modified Crops in Developing Countries." Science 299, no. 5608(2003): 900-902.

Rohrbach, D., and P. Malusalila (2000) Develoing rural retail trade of seed through small packs. Matopos Research Station, Zimbabwe.

Roumasset, J. A. Rice and risk : decision-making among low-income farmers. Amsterdam ; New York: sole distributors for the U.S.A. and Canada American Elsevier Pub. Co., 1976.

Sahn, D., D. Stifel, and S. Younger (1999) Inter-temporal Changes in Welfare: Preliminary Results from Nine African Countries.

Thirtle, C., et al. "Can GM-Technologies Help the Poor? The Impact of Bt Cotton in Makhathini Flats, KwaZulu-Natal." World Development 31, no. 4(2003): 717-32.

Traxler, G., et al. "Production Risk and the Evolution of Varietal Technology." American Journal of Agricultural Economics 77, no. 1(1995): 1-7. 
Tripp, R. "Can Biotechnology Reach the Poor? The Adequacy of Information and Seed Delivery." Food Policy 26, no. 3(2001): 249-64.

Tripp, R., and S. Pal. "Information and Agricultural Input Markets: Pearl Millet Seed in Rajasthan." Journal of International Development 12, no. 1(2000): 133-44.

Wambugu, F. "Why Africa needs agricultural biotech." Nature 400, no. July(1999): 15-16.

White, H. L. "A heteroscedasticity-consistent covariance matrix estimator and a direct test for heteroscedasticity." Econometrica 48(1980): 817-838.

Wood, G. "Staying Secure, Staying Poor: The "Faustian Bargain "." World Development 31, no. 3(2003): 455-71.

World Bank. "World Development Report 2000/01." World Bank.

Zimmerman, F. J., and M. R. Carter. "Asset Smoothing, Consumption Smoothing and the Reproduction of Inequality Under Risk and Subsistence Constraints." Journal of Development Economics 71(2003): 233-260. 


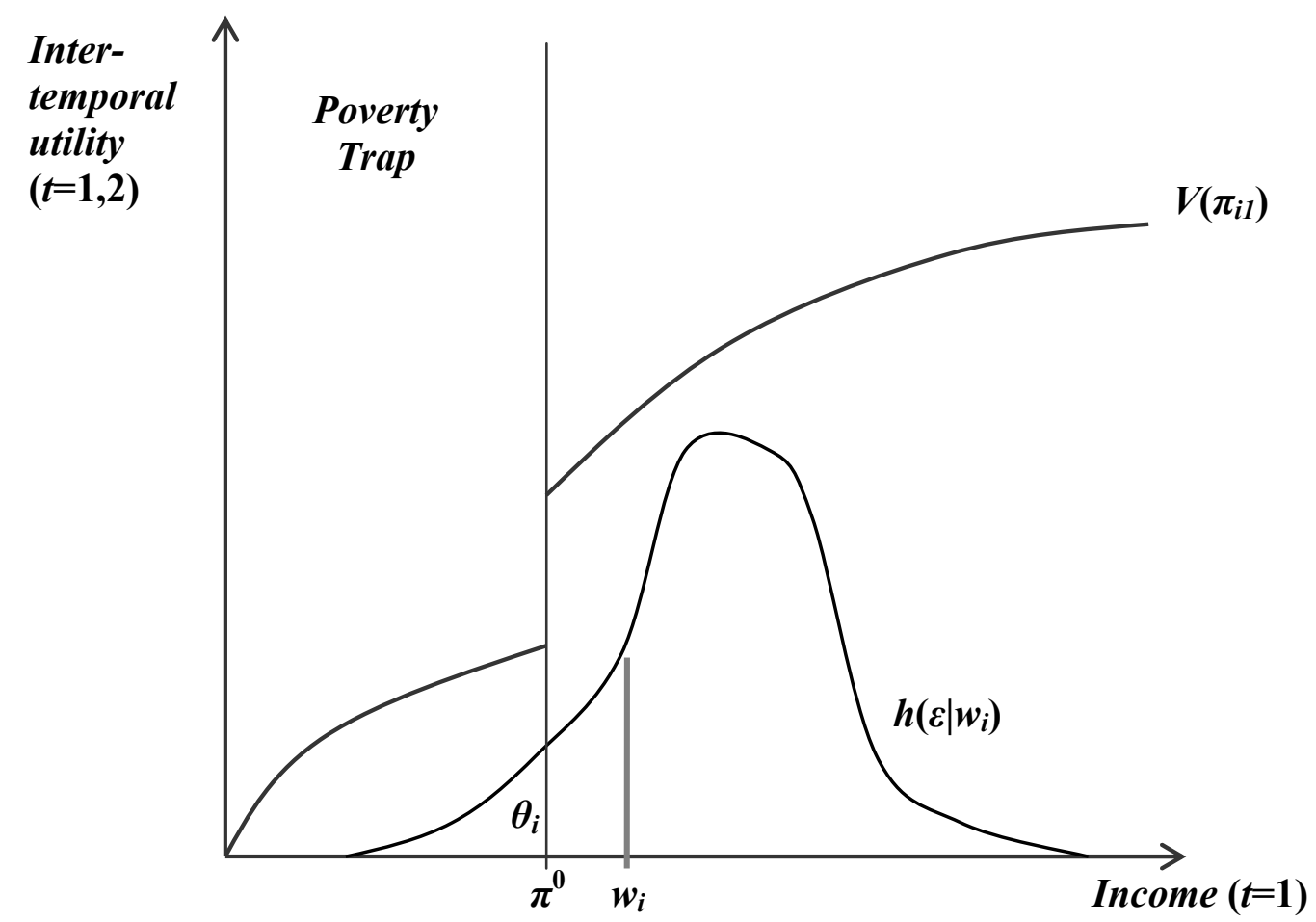

Figure 1 Intertemporal utility with yield pdf superimposed to illustrate the pro-poor benefit of stabilized and truncated yield distributions. 


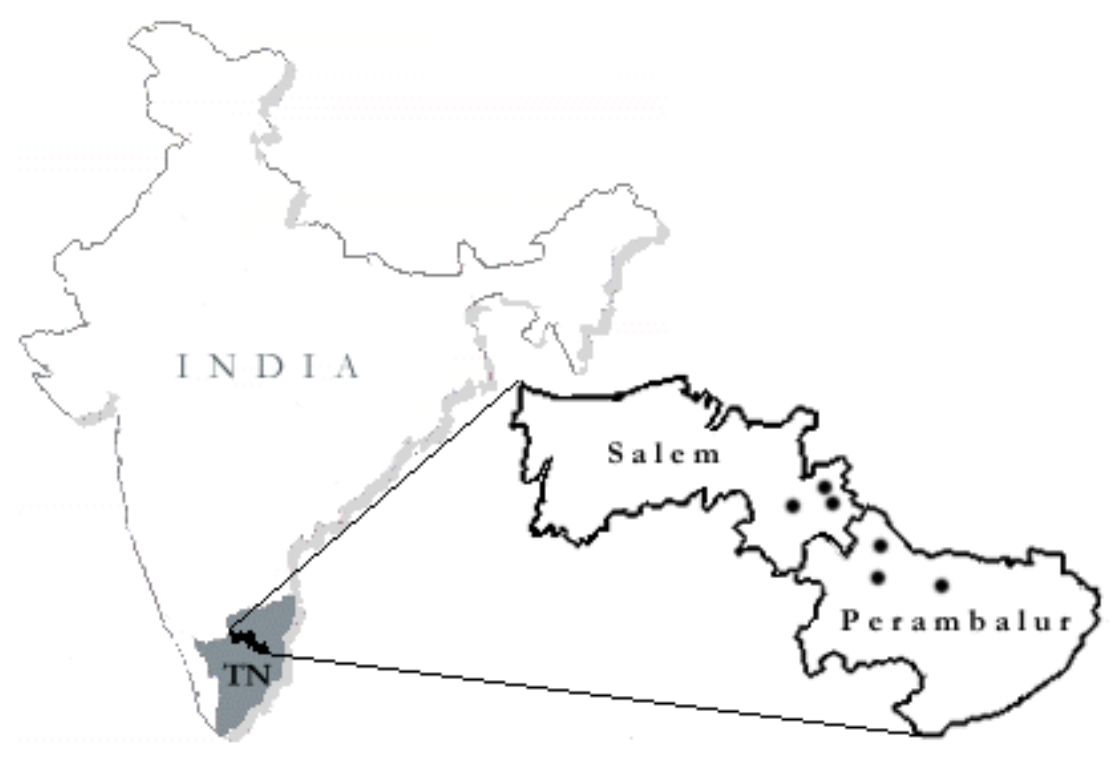

Figure 2 Map of surveyed villages in Salem and Perambalur districts of Tamil Nadu (TN), India (India map courtesy of www.theodora.com/maps, used with permission). 

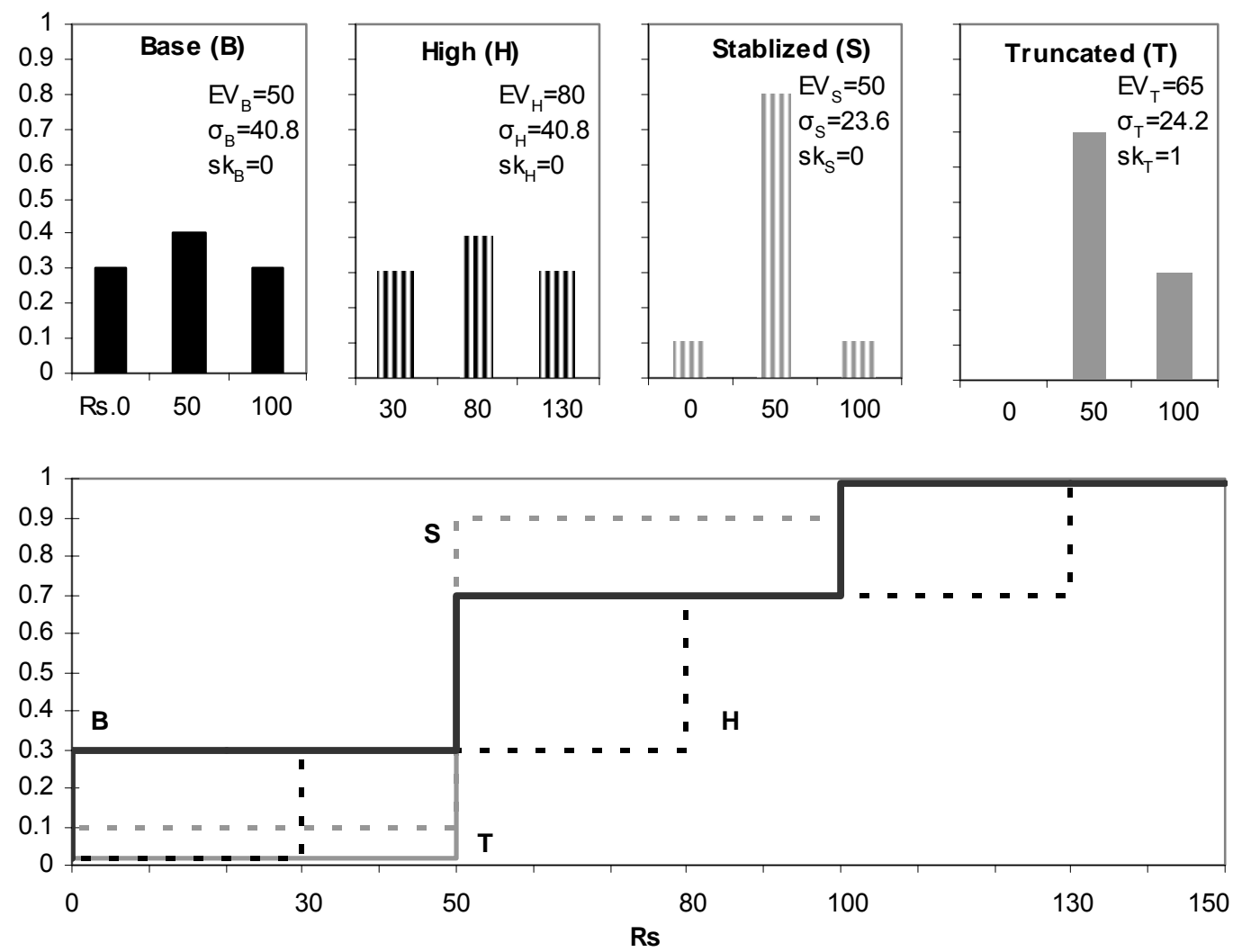

Figure 3 Marginal probability distributions (top) and cumulative probability distributions (bottom) for distribution types in experiment 


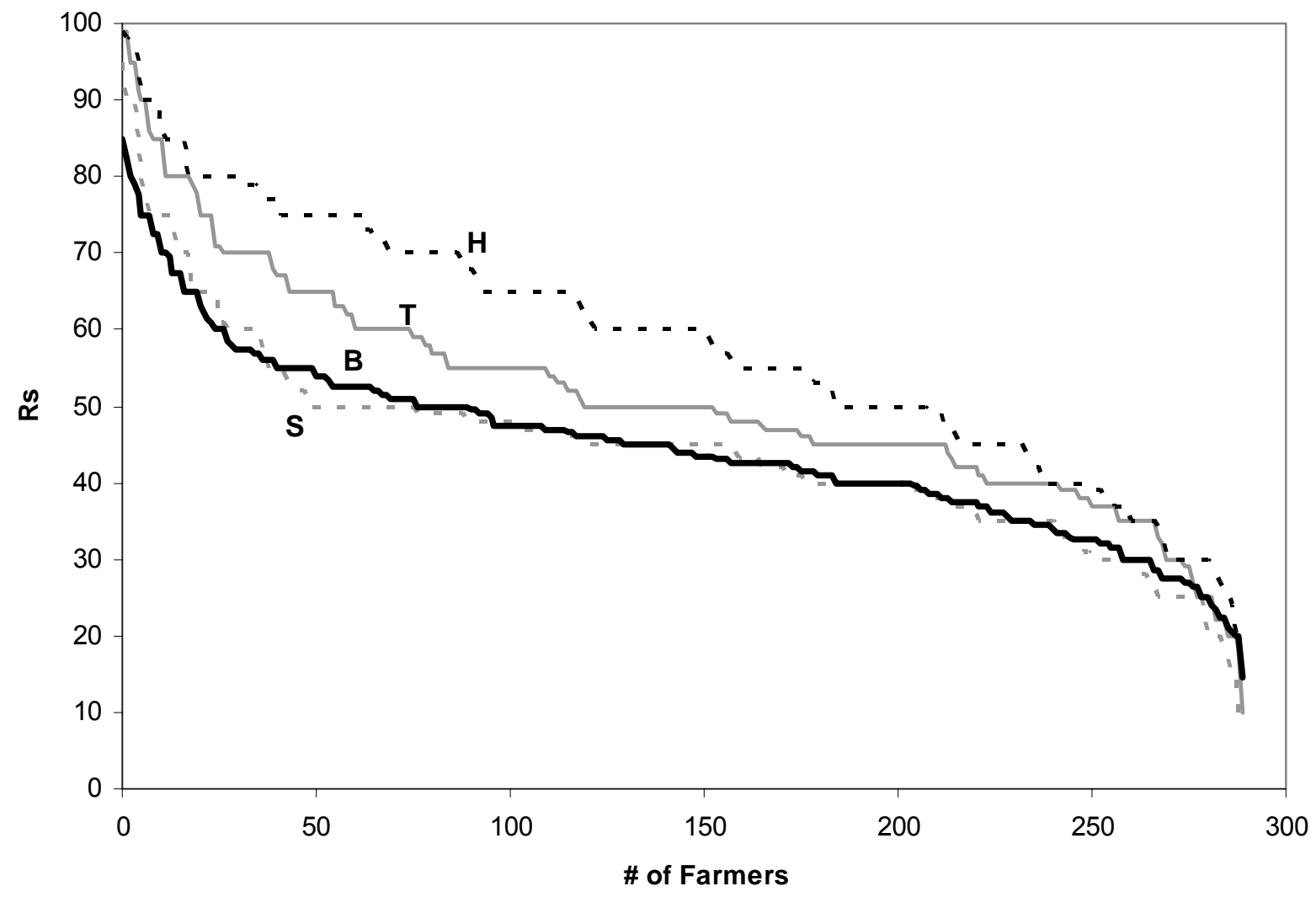

Figure 4 Demand curves for experimental distributions generated as graphs of ordered bid data. 

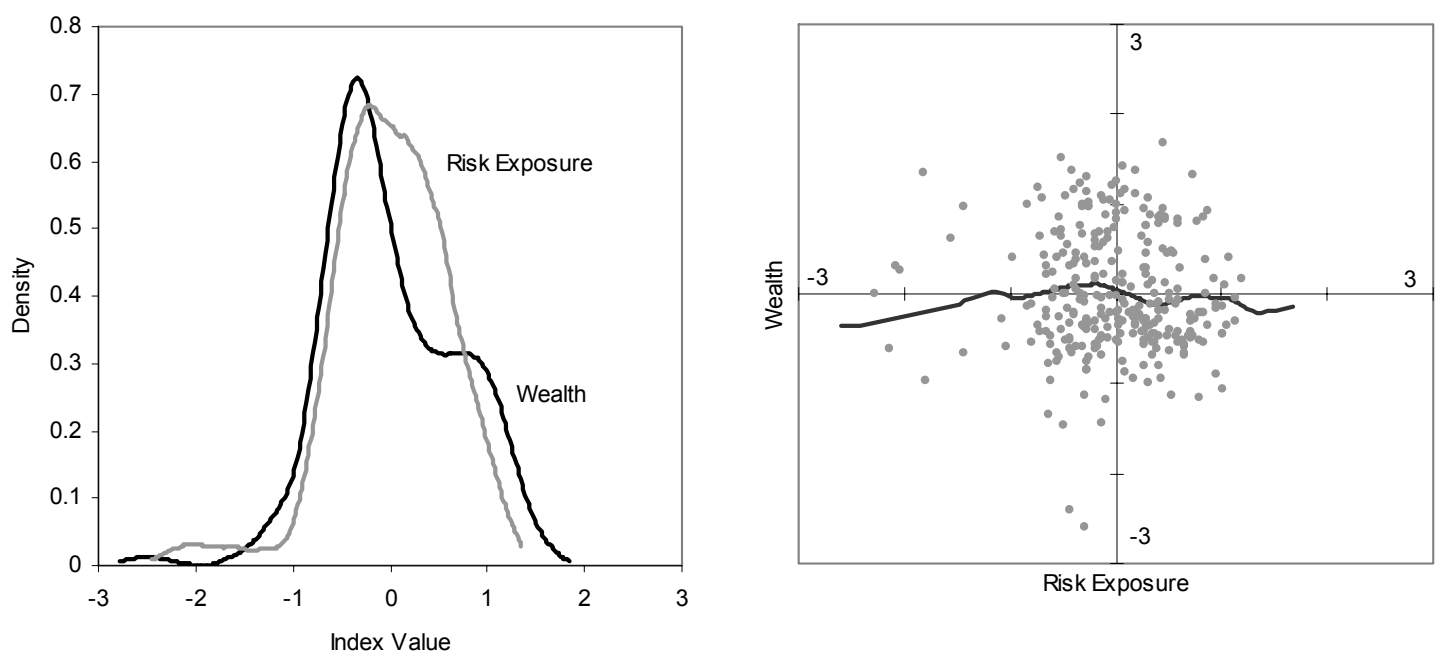

Figure 5 Non-parametric regressions of wealth index and risk exposure index densities (left) and scatter plot of wealth and risk exposure indices (right). 
Table 1 Descriptive statistics for relevant variables

\begin{tabular}{|c|c|c|c|c|c|c|}
\hline & Median & Mean & Std.Dev & Max & Min & \# Min \\
\hline \multicolumn{7}{|c|}{ Household Demographics, Wealth \& Assets } \\
\hline $\mathrm{HH}$ size & 4 & 4.24 & 1.17 & 7 & 2 & \\
\hline Female $\{0,1\}$ & & 0.01 & & & 0 & 287 \\
\hline Age & 45 & 43.64 & 11.39 & 77 & 19 & \\
\hline Education (yrs) & 5 & 4.82 & 4.52 & 20 & 0 & 105 \\
\hline House $w /$ concrete floor $\{0,1\}$ & & 0.87 & & & & \\
\hline Tractor $\{0,1\}$ & & 0.04 & & & & \\
\hline Television $\{0,1\}$ & & 0.33 & & & & \\
\hline Telephone $\{0,1\}$ & & 0.09 & & & & \\
\hline Radio $\{0,1)$ & & 0.73 & & & & \\
\hline Total annual expenses (Rs) $\dagger$ & 6,500 & 11,490 & 14,416 & 118,000 & 0 & 2 \\
\hline Tropical livestock units & 2 & 1.80 & 1.66 & 10 & 0 & 66 \\
\hline Land (acres) & 5 & 6.67 & 5.60 & 50 & 0 & 1 \\
\hline$\%$ irrigated land & $25 \%$ & $33 \%$ & $36 \%$ & $100 \%$ & 0 & 115 \\
\hline$\%$ in cotton & $24 \%$ & $28 \%$ & $29 \%$ & $100 \%$ & 0 & 88 \\
\hline$\%$ in maize & $50 \%$ & $46 \%$ & $33 \%$ & $100 \%$ & 0 & 65 \\
\hline$\%$ in chilies & $0 \%$ & $2 \%$ & $6 \%$ & $67 \%$ & 0 & 254 \\
\hline$\%$ in paddy & $0 \%$ & $8 \%$ & $14 \%$ & $100 \%$ & 0 & 184 \\
\hline \multicolumn{7}{|c|}{ Farm Management Goals (rank) } \\
\hline Increase yield & 1 & 1.3 & 0.7 & & & \\
\hline Stabilize yield & 4 & 4.1 & 1.3 & & & \\
\hline Protect against crop loses & 3 & 2.7 & 1.1 & & & \\
\hline Lower production costs & 3 & 3.6 & 1.4 & & & \\
\hline Increase harvest quality & 4 & 4.2 & 1.2 & & & \\
\hline Efficiently use water & 6 & 5.0 & 1.5 & & & \\
\hline \multicolumn{7}{|c|}{ Risk Exposure of Productive Income } \\
\hline \% income from 'very risky' sources & 40 & 36 & 33 & 100 & 0 & 109 \\
\hline$\%$... from 'no risk' sources & 0 & 6 & 18 & 100 & 0 & 244 \\
\hline$\%$... exposed to high weather risk & 40 & 39 & 35 & 100 & 0 & 104 \\
\hline$\%$...exposed to high market risk & 30 & 35 & 37 & 100 & 0 & 129 \\
\hline$\%$...exposed to high pest risk & 40 & 37 & 31 & 100 & 0 & 89 \\
\hline \multicolumn{7}{|c|}{ High-Stakes WTP in Experiment } \\
\hline Average $[$ Base $(B)] \ddagger$ & 44 & 45 & 12 & 85 & 14.5 & \\
\hline High $(H)$ & 60 & 58 & 17 & 99 & 20 & \\
\hline Stabilized (S) & 45 & 44 & 13 & 95 & 10 & \\
\hline Truncated $(\mathrm{T})$ & 50 & 51 & 15 & 99 & 10 & \\
\hline Total earnings from experiment (Rs) & 63 & 64 & 11 & 135 & 44 & \\
\hline
\end{tabular}


Table 2 Estimation results for treatment effect models with farmer fixed-effects and standard errors corrected for between-farmer heteroscedasticity.

\begin{tabular}{|c|c|c|c|c|c|c|c|c|}
\hline \multirow[t]{3}{*}{ Model: } & \multicolumn{4}{|c|}{ WTP (Rs) } & \multicolumn{2}{|c|}{$\Delta$ WTP over B (Rs) } & \multicolumn{2}{|c|}{$\Delta$ wtp over B (\%) } \\
\hline & \multirow[b]{2}{*}{ Coeff. } & \multicolumn{3}{|c|}{ Risk Premium (RP) } & \multirow[b]{2}{*}{ Coeff. } & \multirow[b]{2}{*}{ Std.Err. } & \multirow[b]{2}{*}{ Coeff. } & \multirow[b]{2}{*}{ Std.Err } \\
\hline & & Std.Err. & Rs & $\mathrm{rp}=\mathrm{RP} / \mathrm{EV}$ & & & & \\
\hline & \multicolumn{8}{|c|}{$====$ All Farmers $====$} \\
\hline Constant $^{\dagger}$ & $43.9^{* *}$ & 1.34 & 6 & $12 \%$ & -2.8 * & 1.4 & -2.1 & 3.7 \\
\hline Higher $(\mathrm{H})$ & 13.2 ** & 0.9 & 23 & $29 \%$ & 13.4 ** & 0.9 & $31.4^{* *}$ & 2.5 \\
\hline Stabilized (S) & -0.40 & 0.85 & 7 & $13 \%$ & & & & \\
\hline Truncated $(\mathrm{T})$ & $6.3^{* *}$ & 0.84 & 15 & $23 \%$ & $6.5^{* *}$ & 0.9 & 14.6 ** & 2.2 \\
\hline Previous Play $\{0,1\}$ & -0.30 & 0.81 & & & & & & \\
\hline Previous Earnings & 0.02 & 0.01 & & & 0.04 * & 0.02 & 0.10 * & 0.04 \\
\hline Adj- $R^{2}$ & \multicolumn{2}{|l|}{0.34} & & & \multicolumn{2}{|l|}{0.40} & \multicolumn{2}{|l|}{0.38} \\
\hline $\mathrm{N}=$ & \multicolumn{2}{|l|}{1450} & & & \multicolumn{2}{|l|}{870} & \multicolumn{2}{|l|}{870} \\
\hline & \multicolumn{8}{|c|}{$====$ Farmers who understood experiment well ${ }^{\ddagger}====$} \\
\hline Constant $^{\dagger}$ & $44.3^{* *}$ & 1.5 & 6 & $11 \%$ & -3.6 * & 1.6 & -2.3 & 3.8 \\
\hline Higher $(\mathrm{H})$ & $13.3^{* *}$ & 0.94 & 22 & $28 \%$ & $14.0^{* *}$ & 1.0 & $33.3^{* *}$ & 2.5 \\
\hline Stabilized (S) & -1.0 & 0.94 & 7 & $13 \%$ & & & & \\
\hline Truncated (T) & $6.4^{* *}$ & 0.93 & 14 & $22 \%$ & $7.2^{* *}$ & 1.0 & $16.7^{* *}$ & 2.3 \\
\hline Previous Play $\{0,1\}$ & -0.5 & 0.90 & & & & & & \\
\hline Previous Earnings & 0.02 & 0.02 & & & 0.042 * & 0.018 & 0.094 * & 0.045 \\
\hline Adj- $R^{2}$ & 0.33 & & & & 0.42 & & 0.42 & \\
\hline $\mathrm{N}=$ & 1220 & & & & 732 & & 732 & \\
\hline
\end{tabular}


Table 3 Estimation results for moment effects models with farmer random-effects.

\begin{tabular}{|c|c|c|c|c|c|c|c|c|}
\hline \multirow{3}{*}{$\begin{array}{r}\text { Model: } \\
\text { L distribution: }\end{array}$} & \multirow{2}{*}{\multicolumn{2}{|c|}{$\begin{array}{l}\text { WTP (Rs) } \\
\text { Excluded }\end{array}$}} & \multirow{2}{*}{\multicolumn{2}{|c|}{$\begin{array}{l}\text { WTP (Rs) } \\
\text { Included }\end{array}$}} & \multirow{2}{*}{\multicolumn{2}{|c|}{$\begin{array}{c}\Delta \text { WTP (Rs) } \\
\text { Included }\end{array}$}} & \multirow{2}{*}{\multicolumn{2}{|c|}{$\begin{array}{l}\Delta \text { wtp }(\%) \\
\text { Included }\end{array}$}} \\
\hline & & & & & & & & \\
\hline & Coeff. & Std.Err. & Coeff. & Std.Err. & Coeff. & Std.Err. & Coeff. & Std.Err \\
\hline & \multicolumn{8}{|c|}{$====$ All Farmers $====$} \\
\hline Constant & 22.6 ** & 2.5 & $21.2 * *$ & 2.3 & $-26.2 * *$ & 2.3 & $-56.0 * *$ & 5.8 \\
\hline EV & $0.44 * *$ & 0.032 & $0.45 * *$ & 0.019 & $0.44 * *$ & 0.019 & $1.07^{* *}$ & 0.049 \\
\hline St.Dev & 0.0170 & 0.055 & -0.0020 & 0.050 & -0.018 & 0.054 & -0.072 & 0.14 \\
\hline Skewness & 0.02 & 1.17 & -0.32 & 1.10 & -0.41 & 1.09 & -1.82 & 2.78 \\
\hline Previous Play $\{0,1\}$ & $-1.9 *$ & 0.86 & $-1.6 *$ & 0.75 & & & & \\
\hline \multirow[t]{3}{*}{ Previous Earnings } & 0.012 & 0.015 & 0.027 * & 0.013 & 0.067 * & 0.017 & 0.13 * & 0.042 \\
\hline & 1450 & & 1740 & & 1160 & & 1160 & \\
\hline & \multicolumn{8}{|c|}{$====$ Farmers who understood experiment well $====$} \\
\hline Constant & $21.5 * *$ & 2.8 & $20.0^{* *}$ & 2.6 & $-25.4 * *$ & 2.2 & $-52.1 * *$ & 5.4 \\
\hline EV & $0.44 * *$ & 0.035 & $0.47^{* *}$ & 0.021 & 0.46 ** & 0.019 & $1.10 * *$ & 0.047 \\
\hline St.Dev & 0.0510 & 0.061 & 0.0204 & 0.055 & 0.002 & 0.050 & -0.142 & 0.12 \\
\hline Skewness & 0.62 & 1.30 & 0.10 & 1.22 & -0.28 & 1.10 & -1.51 & 2.75 \\
\hline Previous Play $\{0,1\}$ & $-2.3 *$ & 0.94 & $-2.2 * *$ & 0.83 & & & & \\
\hline Previous Earnings & 0.009 & 0.016 & 0.021 & 0.015 & 0.035 ** & 0.012 & 0.07 * & 0.029 \\
\hline
\end{tabular}

$\mathrm{N}=$

1220

1474

976

976

${ }^{*}$ indicates significance at $10 \%$ level

** indicates significance at $1 \%$ level 
Table 4 Factor analysis results for wealth and risk exposure indices

\begin{tabular}{|c|c|c|c|c|c|c|c|}
\hline \multirow[b]{2}{*}{ Variable } & \multirow[b]{2}{*}{ Std. Coeff. } & \multirow[b]{2}{*}{ Mean } & \multirow[b]{2}{*}{ Std.Dev. } & \multicolumn{4}{|c|}{ Hypothesis Tests } \\
\hline & & & & Hypotheses & df & ChiSq & $\mathrm{Pr}>\mathrm{ChiSq}$ \\
\hline \multicolumn{8}{|c|}{$==========$ Wealth Index $\dagger==========$} \\
\hline Ln(Non-Irr.Land) & 0.33 & 1.4 & 0.79 & $\mathrm{H}_{0}$ : No common factors & 10 & 40.7 & $<0.0001$ \\
\hline $\operatorname{Ln}(T L U)$ & 0.19 & 0.84 & 0.60 & $\mathrm{H}_{\mathrm{A}}$ : At least one factor & & & \\
\hline Television $\{0,1\}$ & 0.53 & 0.33 & 0.47 & $\mathrm{H}_{0}$ : One factor is sufficient & 5 & 3.6 & 0.61 \\
\hline Concrete floor $\{0,1\}$ & 0.23 & 0.87 & 0.34 & $\mathrm{H}_{\mathrm{A}}:$ More factors needed & & & \\
\hline Ln(Total Expenses) & 0.42 & 8.8 & 1.2 & & & & \\
\hline \multicolumn{8}{|c|}{$=========$ Risk Exposure Index $\ddagger=========$} \\
\hline$\%$ Crop Lost & -0.12 & 63 & 20 & $\mathrm{H}_{0}$ : No common factors & 6 & 17.9 & 0.006 \\
\hline \% Income from 'Very Risky' source & 0.40 & 35 & 33 & $\mathrm{H}_{\mathrm{A}}$ : At least one factor & & & \\
\hline \% Income from 'No Risk' source & -0.31 & 6.2 & 18 & $\mathrm{H}_{0}$ : One factor is sufficient & 2 & 2.8 & 0.23 \\
\hline Ln(Irr.Land) & -0.10 & 0.85 & 0.80 & $\mathrm{H}_{\mathrm{A}}$ : More factors needed & & & \\
\hline
\end{tabular}

$\dagger$ Motorcycle $\{0,1\}$ and Radio $\{0,1\}$ (Tractor $\{0,1\}$ ) were removed after iteration one (two) to reduce multicollinearity.

‡ Log TLU (\% Income in 'worst' season) were removed after iteration one (two) to reduce multicollinearity. 
Table 5 Estimation results for farmer-moment effects models with village fixed-effects and farmer random-effects.

\begin{tabular}{|c|c|c|c|c|c|c|c|c|}
\hline Model: & WTP (Rs & & WTP (R & & $\Delta \mathrm{WTP}(\mathrm{F}$ & & $\Delta$ wtp $(\%$ & \\
\hline L distribution: & Exclude & & Include & & Include & & Includec & \\
\hline & Coeff. & Std.Err. & Coeff. & Std.Err. & Coeff. & Std.Err. & Coeff. & Std.Err. \\
\hline Constant $^{\dagger}$ & $17.3^{* *}$ & 4.2 & $17.8^{* *}$ & 4.0 & -34.5 ** & 4.2 & $-65.0 * *$ & 10.4 \\
\hline EV & $0.49^{* *}$ & 0.045 & $0.46^{* *}$ & 0.026 & $0.45^{* *}$ & 0.026 & $1.1^{* *}$ & 0.067 \\
\hline St.Dev & 0.034 & 0.079 & 0.053 & 0.071 & 0.073 & 0.077 & 0.094 & 0.20 \\
\hline Skewness & -0.88 & 1.7 & -0.56 & 1.6 & -0.72 & 1.6 & -2.7 & 4.0 \\
\hline Wealth & $-6.7^{*}$ & 3.5 & -4.6 & 3.3 & $-5.8 *$ & 3.4 & -12.8 & 8.6 \\
\hline Wealth $x \mathrm{EV}$ & 0.092 * & 0.049 & 0.028 & 0.028 & 0.026 & 0.027 & 0.070 & 0.070 \\
\hline Wealth $x$ St.Dev & 0.05 & 0.085 & 0.11 & 0.077 & 0.16 * & 0.083 & 0.34 * & 0.21 \\
\hline Wealth $x$ Skew & 0.0 & 1.8 & 1.0 & 1.7 & 1.0 & 1.7 & 2.9 & 4.3 \\
\hline Risk Exposure & -1.9 & 4.0 & -3.2 & 3.8 & -1.4 & 3.9 & 7.5 & 9.8 \\
\hline Risk $x$ EV & -0.032 & 0.055 & 0.021 & 0.032 & 0.020 & 0.031 & -0.018 & 0.080 \\
\hline Risk $x$ St.Dev & 0.065 & 0.096 & 0.019 & 0.087 & -0.028 & 0.094 & -0.25 & 0.24 \\
\hline Risk $x$ Skew & 3.61 * & 2.0 & 2.87 & 1.9 & 3.0 & 1.9 & 5.5 & 4.9 \\
\hline Bt Cotton $\{0,1\}$ & 7.9 * & 4.7 & 4.0 & 4.4 & 3.7 & 4.5 & 3.1 & 11.4 \\
\hline Bt Cotton x EV & -0.125 * & 0.065 & 0.008 & 0.037 & 0.009 & 0.037 & -0.010 & 0.094 \\
\hline Bt Cotton x St.Dev & 0.034 & 0.11 & -0.082 & 0.10 & $-0.20 *$ & 0.111 & -0.29 & 0.28 \\
\hline Bt Cotton x Skew & 3.25 & 2.4 & 1.29 & 2.3 & 1.4 & 2.2 & 4.8 & 5.7 \\
\hline Misunderstand $\{0,1\}$ & 5.4 & 6.4 & 8.4 & 6.0 & 9.2 & 6.1 & 28.4 * & 15.5 \\
\hline Misund $x$ EV & 0.01 & 0.1 & $-0.10 *$ & 0.1 & -0.10 * & 0.050 & -0.22 * & 0.13 \\
\hline Misund $x$ St.Dev & -0.20 & 0.2 & -0.11 & 0.1 & 0.002 & 0.151 & -0.20 & 0.38 \\
\hline Misund $x$ Skew & -3.82 & 3.3 & -2.21 & 3.1 & -2.1 & 3.0 & -8.7 & 7.7 \\
\hline Ln(Irr.Land) & -0.14 & 0.77 & -0.32 & 0.74 & 0.02 & 0.84 & -1.4 & 2.0 \\
\hline Education & -0.05 & 0.14 & -0.05 & 0.13 & -0.09 & 0.15 & -0.32 & 0.36 \\
\hline Age & 0.02 & 0.05 & 0.01 & 0.05 & 0.13 & 0.06 & 0.13 & 0.13 \\
\hline Previous Play $\{0,1\}$ & $-1.8 *$ & 0.87 & $-1.5 *$ & 0.76 & & & & \\
\hline \multirow[t]{2}{*}{ Previous Earn } & 0.01 & 0.01 & 0.03 * & 0.01 & 0.07 & 0.02 & 0.14 & 0.04 \\
\hline & \multicolumn{2}{|l|}{1450} & \multicolumn{2}{|l|}{1740} & \multicolumn{2}{|l|}{1160} & \multicolumn{2}{|l|}{1160} \\
\hline
\end{tabular}

†Village fixed-effects results are suppressed.

${ }^{*}$ indicates significance at $10 \%$ level

** indicates significance at $1 \%$ level 